\title{
A Unique Glycine-Rich Motif at the N-terminal Region of Bamboo mosaic virus Coat Protein Is Required for Symptom Expression
}

\author{
Ping Lan, ${ }^{1}$ Wen-Bin Yeh, ${ }^{2}$ Chih-Wei Tsai, ${ }^{1}$ and Na-Sheng Lin ${ }^{1}$ \\ ${ }^{1}$ Institute of Plant and Microbial Biology, Academia Sinica, Taipei, Taiwan 115, Republic of China; ${ }^{2}$ Department of Entomology, \\ National Chung-Hsing University, Taichung, Taiwan 402, Republic of China
}

Submitted 27 February 2010. Accepted 1 March 2010.

\begin{abstract}
The coat proteins (CP) of many plant viruses are multifunctional proteins. We used N-terminal sequencing and mass spectrometry/mass spectrometry analysis to identify a truncated form of the Bamboo mosaic virus (BaMV) $\mathrm{CP}$ missing the N-terminal 35 amino acids (N35). The N35 region is unique in the potexviruses by its containing a glycine-rich motif (GRM) not present in databases but highly conserved among BaMV isolates. Results from sitedirected mutagenesis and deletion mutational analysis showed that loss of this region converted necrotic local lesions to chlorotic local lesions on Chenopodium quinoa leaves. Furthermore, this region is required for successful development of mosaic symptoms on Nicotiana benthamiana leaves but is dispensable for $\mathrm{BaMV}$ replication and cell-to-cell and long-distance movement as well as virion assembly. This unique GRM-containing region of BaMV CP may be a symptom determinant in specific hosts.
\end{abstract}

Increasing evidence shows that coat proteins $(\mathrm{CP})$ of many plant viruses play multifunctional roles in almost every step of the viral infection cycle. These roles include delivery of the virus into the plant cell, disassembly of virus particles, translation of viral RNA, viral genome replication, assembly of progeny virus, virus movement between plant cells or long-distance movement in the plant, and interactions with the host plant to activate or suppress the host defenses, thus resulting in susceptibility, disease symptoms, or resistance (Bol 2005). For example, in the genus Potexvirus, $\mathrm{CP}$ is involved in virion assembly and is required for virus cell-to-cell and long-distance movement (Verchot-Lubicz et al. 2007). The CP of Potato virus $X$ (PVX) is involved in genomic RNA accumulation (Chapman et al. 1992) and is responsible for induction of the Rx resistance system in potato plants (Goulden and Baulcombe 1993).

The $\mathrm{N}$ - and $\mathrm{C}$-terminal regions of the $\mathrm{CP}$ of potexviruses are varied in amino acids, although the central region is highly conserved (Abouhaidar and Lai 1989). The variability of amino-acid residuals at the $\mathrm{N}$ terminus of potexvirus $\mathrm{CP}$ results in the low serological cross-reactivity among potexviruses (Koenig and Torrance 1986). Moreover, the N-terminal region may be highly sensitive to the action of plant sap proteases, and proteolytic cleavage of PVX CP may occur in situ (Koenig et al. 1970, 1978), which results in the formation of an N-terminal truncated PVX CP (Koenig et al. 1970). Such an $\mathrm{N}$-terminal-truncated $\mathrm{CP}$ has been found in another potexvirus, Papaya mosaic virus (PMV), in that a large proportion of the PMV CP of the purified virus lacked several amino acids at the $\mathrm{N}$ terminus (Zhang et al. 1993). However, whether this truncated $\mathrm{CP}$ is formed in vivo or during the processes of purification is unclear. In vitro data showed that this N-terminal region can be easily removed by mild trypsin treatment without disrupting the virion structure (Tremaine and Agrawal 1972). Further analysis showed that deletion of the N-terminal 30 amino acids of PVX CP did not substantially affect cell-to-cell movement (Chapman et al. 1992; Lico et al. 2006).

Bamboo mosaic virus (BaMV), a member of the Potexvirus genus, possesses a single-strand, positive-sense RNA genome of approximately $6.4 \mathrm{~kb}$ and contains five conserved open reading frames (ORF) (Lin et al. 1994). ORF1 encodes a 155$\mathrm{kDa}$ replication-related protein with three functional domains: an N-terminal mRNA capping enzyme, a central RNA helicase, and a C-terminal RNA-dependent RNA polymerase (RdRp) (Huang et al. 2005; Li et al. 2001a and b). ORF2 through ORF4 encode movement proteins of 28, 13, and 6 $\mathrm{kDa}$, respectively. These three ORF overlap in the genome and, thus, are called the triple gene block. The $25-\mathrm{kDa} \mathrm{CP}$ is encoded by ORF5. The $155-\mathrm{kDa}$ protein is directly translated from genomic RNA, whereas CP is translated from the subgenomic RNA of approximately $1.0 \mathrm{~kb}$. Recently, BaMV has been successfully developed as a plant-expression vector by replacing the N-terminal 35 amino acids (N35) of BaMV CP with a 37-amino acid peptide of the foot and mouth disease virus VP1. Recombinant BaMV expressing VP1 epitope induced positive immunity in swine. However, this chimeric virus causes a different symptom phenotype in Nicotiana benthamiana and Chenopodium quinoa (Yang et al. 2007).

Recently, Ozeki and associates (2009) suggested that the Nterminal region of potexvirus $\mathrm{CP}$ could be separated into two distinct functional domains: an $\mathrm{N}$-extra $(\mathrm{Nex})$ region and an $\mathrm{N}$ core region. The latter region is required for cell-to-cell movement but is dispensable for virion assembly, as in Plantago asiatica mosaic virus (PlAMV). The former region is dispensable for both cell-to-cell movement and virion assembly. However, the exact role of the Nex region is unknown.

In the present study, we used one- and two-dimensional (1and 2-D, respectively) sodium dodecyl sulfate-polyacrylamide gel electrophoresis (SDS-PAGE), N-terminal sequencing, and tandem mass spectrometry (MS/MS) to identify a major truncated BaMV CP lacking the N35. This region contains a unique glycine-rich motif (GRM) in the potexvirus group, which belongs to the Nex region of potexvirus $\mathrm{CP}$ (Ozeki et al. 2009). We found that this region is required for necrotic local lesion induction in $C$. quinoa and symptom expression in $N$. benthamiana. 


\section{RESULTS}

\section{Identification and characterization} of a major truncated BaMV CP.

Initially, to elucidate whether the BaMV $\mathrm{CP}$ has any posttranslational modifications, one-dimensional (1-D) SDS-PAGE of the purified BaMV virions and 2-D electrophoresis of BaMV $\mathrm{CP}$ isolated from purified $\mathrm{BaMV}$ virions were performed.

Freshly prepared (Fig. 1A, lane 1) and stored virions (Fig. 1A, lane 2) were used for 1-D SDS-PAGE analysis. Besides the full-length CP (Fig. 1A, lanes 1 and 2, labeled a), a major truncated CP (Fig. 1A, lanes 1 and 2, labeled b) was always detected by SDS-PAGE, and this was confirmed by Western blot with rabbit anti-BaMV CP (Fig. 1B, lanes 1 and 2). Interestingly, a more truncated $\mathrm{CP}$ was detected from stored virions (Fig. 1A and B, lane 2) than from freshly prepared ones (Fig. 1A and $\mathrm{B}$, lane 1). In contrast, the recombinant $\mathrm{CP}(\mathrm{rCP})$ (Fig. 1A and $\mathrm{B}$, lane 3, labeled c) did not show truncated $\mathrm{CP}$ accumulation (Fig. 1A and B, lane 3), even after storage for a longer time (data not shown). Furthermore, both full-length and truncated

A
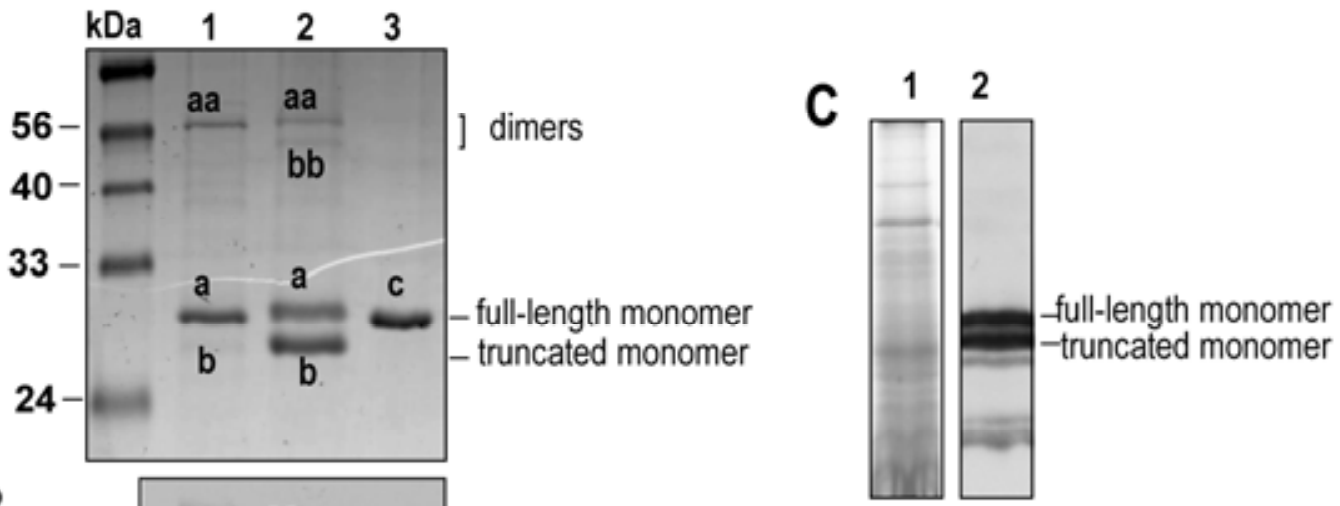

B
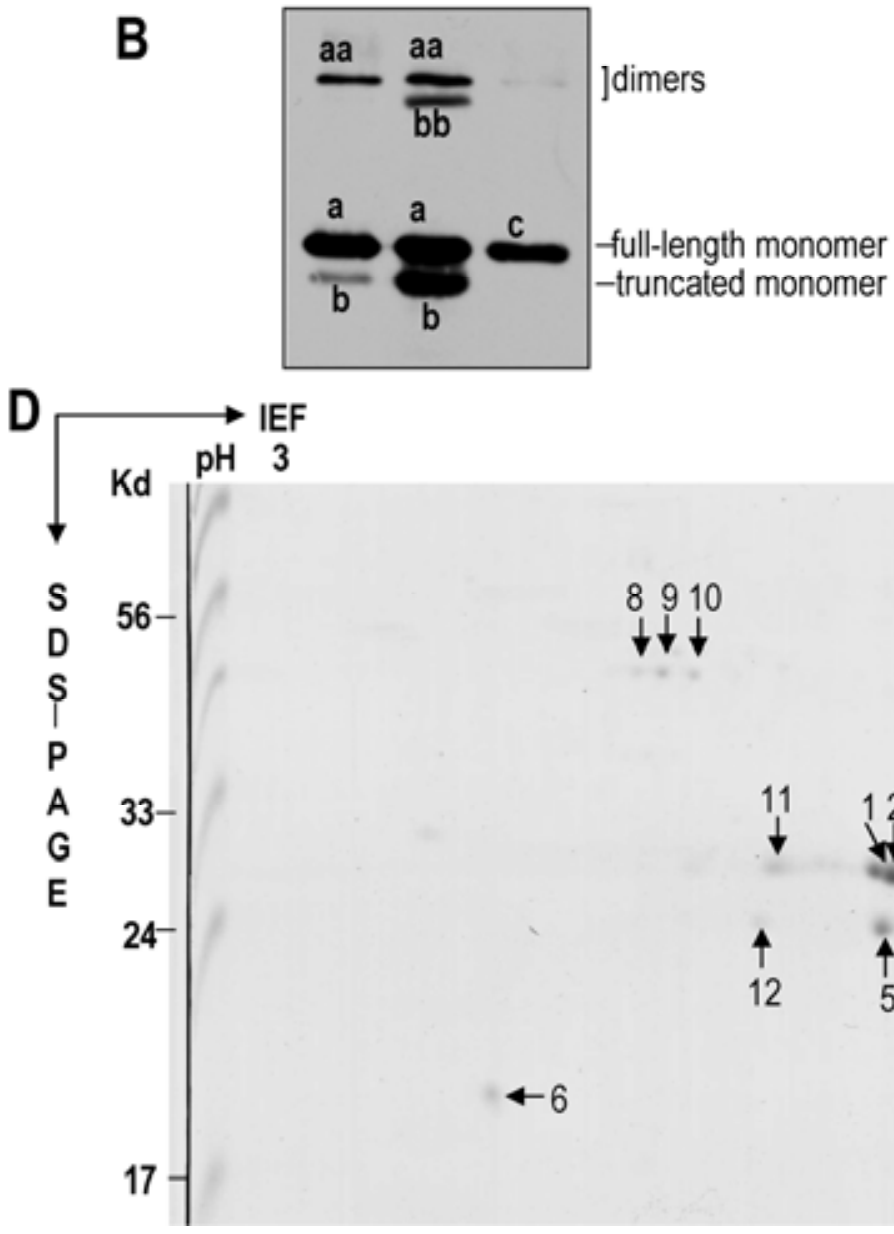

\section{西}
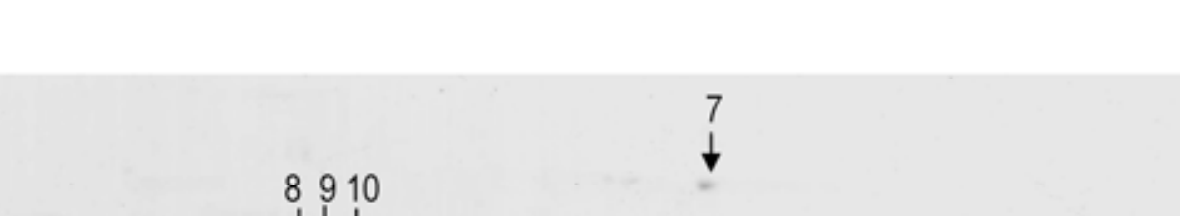

Fig. 1. One-dimensional (1-D) sodium dodecyl sulfate-polyacrylamide gel electrophoresis (SDS-PAGE) and Western blot analysis of coat protein (CP) from purified Bamboo mosaic virus (BaMV) virions or infected leaves of bamboo (Bambusa vulgaris Schrad), as well as 2-D SDS-PAGE of CP isolated from purified BaMV virions. A, 1-D SDS-PAGE of BaMV virions. Freshly prepared BaMV virions (lane 1), BaMV virions stored at $-70^{\circ} \mathrm{C}$ for 6 months (lane 2 ), and recombinant CP purified from Escherichia coli (lane 3) were used for 12\% SDS-PAGE. B, Western blot analysis of BaMV CP. Protein samples were transferred to polyvinylidene difluoride membrane and were probed with polyclonal rabbit anti-BaMV CP at 1:5,000 and then with peroxidase-labeled goat anti-rabbit immunoglobulin G at 1:10,000. Signals were visualized with an enhanced chemiluminescence kit. C, CP accumulation in infected bamboo leaves was tested by 1-D SDS-PAGE (lane 1) and Western blot analysis (lane 2) as described in A and B. D, Proteomic assay of BaMV CP. Approximately $50 \mu \mathrm{g}$ of $\mathrm{CP}$ isolated from freshly purified $\mathrm{BaMV}$ virions was subjected to 2-D electrophoresis. The $\mathrm{pH}$ range (3 to $10 \mathrm{NL}$ ) of the immobilized $\mathrm{pH}$ gradient strip (GE Healthcare) is shown on the top of the gel image. The spots numbered 1 to 12 on the gel were selected for matrix-assisted laser desorption ionization-time of flight-based mass spectrometry or tandem mass spectrometry. 
CP formed dimers (Fig. 1A, lanes 1 and 2, aa and bb), which was further confirmed by Western blot analysis (Fig. 1B, lanes 1 and 2). However, only a faint dimer was observed from $\mathrm{rCP}$ (Fig. 1A and B, lane 3). Such truncated CP was also observed in total proteins extracted directly from BaMV-infected leaves of different hosts, including bamboo, C. quinoa, and N. benthamiana (Fig. 1C and data not shown).

To examine whether truncation of the $\mathrm{CP}$ occurred at the $\mathrm{N}$ or $\mathrm{C}$ terminus, or both, we performed $\mathrm{N}$-terminal sequencing and MS/MS analysis. For N-terminal sequencing, two independent experiments with different virion preparations were carried out. The direct protein sequencing showed that the residues obtained were identical to those starting from the N-terminal 36 amino acids of BaMV CP (Table 1, band b), which suggests that the truncated CP lacked the N35 region. The same peptides as those from the truncated $\mathrm{CP}$ were obtained by N-terminal sequencing from dimers formed by the truncated $\mathrm{CP}$ (Table 1, band bb), which indicated that the truncated $\mathrm{CP}$ was still able to form a dimer. However, no results could be obtained for the full-length $\mathrm{CP}$ or dimers from the full-length $\mathrm{CP}$ by $\mathrm{N}$-terminal sequencing (Table 1, bands a and aa). Failure of $\mathrm{N}$-terminal sequencing led us to suspect that the $\mathrm{CP}$ from virions is modified, and this modification blocks $\mathrm{N}$-terminal sequencing. Therefore, we performed N-terminal sequencing of rCP. Indeed, we could sequence the N-terminal sequence of $\mathrm{rCP}$ in two separate experiments, and the results were as expected (Table 1, band c).

Next, to determine whether the $\mathrm{C}$ terminus of the truncated $\mathrm{CP}$ is intact, MS/MS analysis was performed. Both the monomer and dimer from the truncated $\mathrm{CP}$ still covered the $\mathrm{C}$-terminal but not the N-terminal peptide (Table 2, bands $b$ and $b b$ ).

Table 1. Peptides identified by N-terminal sequence

\begin{tabular}{ll}
\hline Bands & \multicolumn{1}{c}{ Peptides $^{\mathbf{a}}$} \\
\hline $\mathrm{a}$ & Failure \\
aa & Failure \\
$\mathrm{b}$ & AAAQPWEAIF and AAAQPWEAIFTKDDL \\
$\mathrm{bb}$ & AAAQPWEAIF and AAAQPWEAIFTKDDL \\
$\mathrm{c}$ & SGAGT and SGAGTGTGRG \\
\hline
\end{tabular}

${ }^{a} \mathrm{~N}$-terminal amino acid sequences determined by Edman degradation methodology with different Bamboo mosaic virus purification in two different experiments.
In contrast, both nearly intact $\mathrm{N}$ - and $\mathrm{C}$-terminal peptides were covered on MS/MS analysis of the full-length $\mathrm{CP}$ and the dimer from the full-length CP (Table 2, bands a and aa). Thus, $\mathrm{N}$-terminal sequencing, MS/MS analysis, and the shift of proteins on SDS-PAGE confirmed that the truncated CP lacks only the N-terminal region.

To provide more information about the BaMV CP, CP was isolated from the freshly purified virions and was separated by 2-D SDS-PAGE. Multiple forms of CP were observed on 2-D gel. The major truncated CP (Fig. 1D, spot 5) and a faint one (Fig. 1D, spot 12) with similar molecular mass but different isoelectric points $(\mathrm{pI})$ were displayed. The full-length CP (Fig. 1D, spots 1 to 4 and 11) was shown as serial spots (with similar molecular mass but different pI). On 2-D gel, dimers formed from truncated CP (Fig. 1D, spots 8 to 10), and full-length $\mathrm{CP}$ (Fig. 1D, spot 7) appeared, even though the $\mathrm{CP}$ was prepared in a highly denaturing buffer system, that is, $8 \mathrm{M}$ urea, 2\% CHAPS (3-[(3-cholamidopropyl)-dimethylammonio]-1-propanesulfonate), and $40 \mathrm{mM}$ DTT (dithiothreitol) (Fig. 1D). Interestingly, the dimers formed from truncated $\mathrm{CP}$ but not the full-length $\mathrm{CP}$ were displayed as a series of spots (Fig. 1D, spots 8 to 10). In addition, a more extensively truncated CP (Fig. 1D, spot 6) appeared. All spots were analyzed by MS/MS assay, and all spots were BaMV CP. Spots 1 to 4 and 11 were identified as full-length $\mathrm{CP}$, with high protein coverage of more than $78 \%$ and both $\mathrm{N}$ - and $\mathrm{C}$-terminal regions covered (Table 2, spots 1 to 4 and 11). Spots 5, 6, and 12 were identified as the truncated $\mathrm{CP}$ lacking the N-terminal region (spots 5 and 12) or both $\mathrm{N}$ - and $\mathrm{C}$ terminal regions (spot 6) (Table 2). In general, spots corresponding to the dimers formed by truncated CP had low protein coverage, less than $30 \%$ (Table 2 , spots 8 to 10 ), whereas the dimer formed from the full-length $\mathrm{CP}$ had high protein coverage, with both $\mathrm{N}$ - and $\mathrm{C}$-terminal regions covered (Table 2, spot 7). MS/MS spectra revealed no modifications at the $\mathrm{N}$ terminus of BaMV $\mathrm{CP}$, although spot 1 was identified to be a phosphorylated $\mathrm{CP}$ at the $\mathrm{C}$ terminus (data not shown).

\section{The $\mathbf{N 3 5}$ region contains a unique GRM.}

The N35 region contains a GRM (19 glycines out of the 35 amino acids) that could form a coiled-coil structure as predicted by Pôle BioInformatique Lyonnaise network program sequence analysis software. Phylogenetic analysis of $\mathrm{CP}$ of the potexvirus group revealed that although BaMV is closely

Table 2. Tandem mass spectrometry identification of the Bamboo mosaic virus (BaMV) coat protein (CP) from one- and two-dimensional gels

\begin{tabular}{|c|c|c|c|c|}
\hline Bands and spots & GI number ${ }^{a}$ & Protein name & Protein covered $(\%)$ & Amino-acid sequence matched to BaMV CP \\
\hline $\mathrm{BaMV} \mathrm{CP}$ & 2407623 & \multicolumn{3}{|c|}{$\begin{array}{l}{ }^{1} \text { MSGAGTGTGRGTGTGVGGTGGTGGTGGGGTGRGQQAAAQPWEAIFTKDDLAAIEPKPASANVPNTKQWI } \\
\text { GIQAGLIKAGATDANFMKVLLGLSLEAFDRGSSEATTWDGITEGVEHRAAANAIKEANCPIHKVTYYLAKP } \\
\text { TFAIRQSKNLPPANFAKKNVPSQYKWCAFDAFDGLYDPTCLASELPYDAPSEIDRMAYATFKTIQIKIANDQ } \\
\text { KGFNLNYNPNVTQARLPN APLPALPEPTSD }{ }^{242}\end{array}$} \\
\hline $\mathrm{a}$ & 2407623 & BaMV CP & 53.31 & $G^{11}-R^{32}, D^{48}-K^{66}, A^{78}-R^{99}, E^{125}-R^{145}, N^{149}-K^{157}, M^{196}-K^{202}, G^{214}-D^{242}$ \\
\hline aа & 2407623 & BaMV CP & 38.84 & $G^{11}-R^{32}, D^{48}-K^{66}, G^{100}-R^{117}, I^{208}-D^{242}$ \\
\hline $\mathrm{b}$ & 2407623 & BaMV CP & 29.75 & $\mathrm{D}^{48}-\mathrm{K}^{66}, \mathrm{G}^{100}-\mathrm{R}^{117}, \mathrm{I}^{208}-\mathrm{D}^{242}$ \\
\hline $\mathrm{bb}$ & 2407623 & BaMV CP & 14.05 & $\mathrm{D}^{48}-\mathrm{K}^{66}, \mathrm{~L}^{228}-\mathrm{D}^{242}$ \\
\hline 1 & 2407623 & BaMV CP & 86.36 & $\mathrm{M}^{1}-\mathrm{R}^{145}, \mathrm{~N}^{149}-\mathrm{K}^{165}, \mathrm{M}^{196}-\mathrm{D}^{242}$ \\
\hline 2 & 2407623 & BaMV CP & 80.17 & $\mathrm{M}^{1}-\mathrm{R}^{117}, \mathrm{~V}^{133}-\mathrm{R}^{145}, \mathrm{~N}^{149}-\mathrm{K}^{165}, \mathrm{M}^{196}-\mathrm{D}^{242}$ \\
\hline 3 & 2407623 & BaMV CP & 78.93 & $\mathrm{M}^{1}-\mathrm{R}^{145}, \mathrm{E}^{125}-\mathrm{R}^{145}, \mathrm{~N}^{149}-\mathrm{K}^{165}, \mathrm{M}^{196}-\mathrm{K}^{202}, \mathrm{G}^{214}-\mathrm{D}^{242}$ \\
\hline 4 & 2407623 & BaMV CP & 93.39 & $M^{1}-R^{145}, E^{125}-R^{145}, N^{149}-K^{207}, G^{214}-D^{242}$ \\
\hline 5 & 2407623 & BaMV CP & 49.17 & $\mathrm{D}^{48}-\mathrm{K}^{66}, \mathrm{~V}^{88}-\mathrm{R}^{99}, \mathrm{E}^{125}-\mathrm{K}^{132}, \mathrm{P}^{140}-\mathrm{R}^{145}, \mathrm{~K}^{158}-\mathrm{K}^{202}, \mathrm{G}^{214}-\mathrm{D}^{242}$ \\
\hline 6 & 2407623 & BaMV CP & 10.74 & $\mathrm{~V}^{88}-\mathrm{R}^{99}, \mathrm{G}^{214}-\mathrm{R}^{227}$ \\
\hline 7 & 2407623 & BaMV CP & 71.90 & $\mathrm{M}^{1}-\mathrm{R}^{117}, \mathrm{~V}^{133}-\mathrm{R}^{145}, \mathrm{~K}^{158}-\mathrm{K}^{165}, \mathrm{M}^{196}-\mathrm{K}^{202}, \mathrm{G}^{214}-\mathrm{D}^{242}$ \\
\hline 8 & 2407623 & BaMV CP & 12.81 & $\mathrm{P}^{57}-\mathrm{K}^{66}, \mathrm{M}^{196}-\mathrm{K}^{202}, \mathrm{G}^{214}-\mathrm{R}^{227}$ \\
\hline 9 & 2407623 & BaMV CP & 13.22 & $P^{57}-K^{66}, A^{78}-R^{99}$ \\
\hline 10 & 2407623 & BaMV CP & 11.98 & $\mathrm{D}^{48}-\mathrm{K}^{66}, \mathrm{~A}^{78}-\mathrm{K}^{87}$ \\
\hline 11 & 2407623 & BaMV CP & 78.93 & $\mathrm{M}^{1}-\mathrm{R}^{117}, \mathrm{E}^{125}-\mathrm{R}^{145}, \mathrm{~N}^{149}-\mathrm{K}^{165}, \mathrm{M}^{196}-\mathrm{K}^{207}, \mathrm{G}^{214}-\mathrm{D}^{242}$ \\
\hline 12 & 2407623 & BaMV CP & 34.30 & $D^{48}-K^{66}, V^{88}-R^{99}, E^{125}-K^{132}, K^{158}-K^{165}, M^{196}-K^{202}, G^{214}-D^{242}$ \\
\hline
\end{tabular}

${ }^{a}$ Assigned by the National Center for Biotechnology Information.

${ }^{\mathrm{b}} \mathrm{BaMV} \mathrm{CP}$ amino acid sequence deduced from nucleotide sequence of the BaMV CP open reading frame. 
CVX (AY241392)

ZVX (YP 054406)

PMV (NP-044334)

NdMV (AY800279)

PIAMV (NC 003849)

CsCMV (NP_042699)

HRSV (YP2 $\overline{2} 4089$ )

CYMV (P16486)

CybMV (ABB20690)

PAMV (NP 619750)

NMV (NP 040782)

PpMV (Ā̄Y51618)

WCIMV (DQ784572)

NVX (YP 446996)

PVX (AAV̄ 27212)

HsLV (AAZ15110)

LVX (CAA33396)

SMYEAV (NP 62046)

FMV (NC_001483)

BaMV-S (ĀAB70566)
--MSTTGVQS SQSSGPRSTP QSGPFQTLSS SQLAALS----MSN.A. . . . . T. .V.APA TPS.... TA A. ....-----..KSSMST PNIAF.AI.Q EQMSSIKVDP TSNLLP.-------MALTAA PTTDALAAMT FQVSSPSVPT ASELNTITQ-----MALNTA PTADALAAMA FPVSSPSVPT A.ELDTITS--MATP.STTP TTATITQAAT TPLSALSTAP TDEELS-----MTT. .TTNP IPPQAGT. . SAAFAPLSQE VLETLS---------MTDT KKTLFSAP.D EQLDTL. . TI ESNLVP.ISEL -MGEP----T PAPAATY.AA DPTSAPR.AD LAAIKY.PVT-MVDSKKTET P.VIDASKKT E.SKTSHAGR V.FLSA-----MATPSTQTT DPKPANADLS DPNRAPS.ED LKKIKY-----MADN. P. AA TSG. P. TAQD AGAKAPADF. NPNT. P-----MAT. .ATTP PSLTDI.ALK YISSTVSVA. PAEIEA----MANTSASAAL PAQ.KTDDMT APPDNKD.EA L.YIP------MTTPANTTQ ATG.TTST.T KTAGATPATT .G.FTI-----MATKVADNP .DPNVGEPKA TKPGDNVDPA AAADLF--------MTTFV PDAKTWAD. A YTAQSESVAT AEELQSIATL-MGDQPRPPV PPAP. SNPL. MGSTPPV.PG RTPNPN-----MATQNADVT DATDYKKPPA ETEQKALTIQ PRSNKA-----MSGAGTGTG RGTGTGVGGT GGTGGTGGGG TGRGQQ-----

\begin{tabular}{|c|c|c|c|c|}
\hline BaMV-S & MSGAGTGTGR & GTGTGVGGTG & GTGGTGGGGT & GRGQQ \\
\hline BaMV-O & $\ldots \mathrm{T} \ldots \ldots$ & $\cdots$ & $\cdots \cdots \cdots$ & $\cdots$ \\
\hline BaMV-V & $\ldots \mathrm{T} \ldots \ldots$ & $\ldots$ A. . . & $\ldots$. . . . & $\ldots$ \\
\hline BB2CP & $\ldots \mathrm{T} \ldots \ldots$ & $\ldots$ A.A. . . & $\ldots \mathrm{s} \ldots$. & $\ldots$ \\
\hline BB13CP1 & $\ldots \mathbf{T} \ldots \ldots$ & $\ldots$ A . . . & $\ldots \ldots$ & $\ldots \ldots$ \\
\hline BB30CP & $\ldots$ T.N. . . & $\ldots$. . . . N . & D... P.... & $\cdots$ \\
\hline BB34CP & $\ldots \mathrm{T} \ldots$ & $\ldots \ldots \ldots$ & $\ldots \ldots \ldots$ & $\ldots$ \\
\hline BO3CP1 & $\ldots \mathbf{T} \ldots \ldots$ & $\ldots$ A A . . & $\ldots \ldots$ & $\ldots$ \\
\hline BO14CP1 & . . T.S.... & A. . A A . . & $\ldots \ldots \ldots$ & $\ldots$ \\
\hline BO18CP 2 & $\ldots \mathrm{N} \ldots \ldots$ & $\ldots$ A . . . & $\ldots \ldots \ldots$ & $\ldots$ \\
\hline BO23CP1 & $\ldots \mathbf{T} \ldots$ & $\cdots$ A . . . & $\cdots \cdots \cdots$ & $\cdots \cdots$ \\
\hline $\mathrm{BO} 31 \mathrm{CP}$ & $\ldots \mathrm{T} \ldots \ldots$ & $\ldots$ A $\ldots$ & $\cdots \cdots \cdots$ & $\cdots \cdots$ \\
\hline BV11CP1 & $\ldots \mathbf{T} \ldots \ldots$ & $\ldots$. G... & $\ldots \ldots \ldots$ & $\ldots$ \\
\hline DL15-1-CP1 & $\ldots \mathrm{T} \ldots \ldots$ & $\ldots$. G. . . & $\ldots . . v \ldots$ & $\ldots$ \\
\hline DL25CP & $\ldots \mathrm{T} \ldots .$. & $\ldots$ A . . . & $\cdots \cdots \cdots$ & $\ldots$ \\
\hline S5-CP5 & $\ldots$ T....... & $\ldots$ A. . . & $\ldots \ldots \ldots$ & $\ldots$ \\
\hline BB5CP & $\ldots \mathrm{T} \ldots .$. & $\ldots$. . . . . & ...S.D... & $\ldots$ \\
\hline BB14CP1 & $\cdots T \ldots$ & $\ldots$ A. . . & $\cdots \cdots \cdots$ & $\cdots \cdot$ \\
\hline $\mathrm{BB} 31 \mathrm{CP}$ & $\ldots T \ldots$ & $\ldots \ldots \ldots$ & A. . . . . & $\ldots$ \\
\hline BB35CP & $\ldots \mathrm{T} \ldots$. & $\ldots \ldots$ & 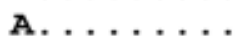 & $\ldots$ \\
\hline BB48CP1 & $\ldots \mathrm{T} \ldots$ & $\ldots$ A. . . & $\cdots \cdots \cdots$ & $\cdots \cdots$ \\
\hline BO11CP2 & . . . . A . & $\ldots$ A $\ldots$ & $\cdots \cdots \cdots$ & $\cdots$ \\
\hline BO15CP1 & $\ldots \mathbf{T} \ldots$. & $\ldots \ldots \ldots$ & $\ldots \ldots$ & $\ldots$ \\
\hline BO19CP1 & $\ldots \mathrm{T} \ldots .$. & $\ldots$ A. . . & $\ldots \ldots$ & $\cdots$ \\
\hline $\mathrm{BO} 29 \mathrm{CP}$ & $\ldots T \ldots$ & $\ldots$ A. . & $\cdots \cdots \cdots$ & $\ldots$ \\
\hline BO32CP1 & $\ldots$ T. . . & N...A. & $\ldots \ldots$ & $\ldots$ \\
\hline BV17CP1 & $\ldots \mathrm{T} \ldots \ldots$ & $\ldots$ A. . . & $\ldots \ldots \ldots$ & $\ldots$ \\
\hline DL22 & $\ldots \mathrm{T} \ldots \mathrm{G}$ & $\ldots$. . . . . & $\ldots \mathrm{S} \ldots \mathrm{A}$ & $\ldots$ \\
\hline S1-CP1 & $\ldots$ T........ & $\ldots$ A. . . & $\cdots \cdots \cdots$ & $\cdots \cdots$ \\
\hline BB12CP1 & $\ldots \mathrm{T} \ldots \mathrm{V}$ & $\ldots \ldots \mathrm{T} \ldots$ & $\ldots \ldots \ldots$ & $\ldots$ \\
\hline BB26CP1 & $\ldots \mathrm{T} \ldots$ & $\ldots$. . . . . & $\ldots s \ldots$ & $\ldots \ldots$ \\
\hline BB42CP & $\ldots \mathrm{T} \ldots \ldots$ & $\ldots \ldots \ldots$ & $\ldots \ldots \ldots$ & $\ldots$ \\
\hline BL & $\ldots \mathrm{T} \ldots \ldots$ & $\ldots$ A. . . & $\ldots$. . . . & $\ldots$ \\
\hline $\mathrm{BO} 13 \mathrm{CP}$ & $\ldots \mathrm{T} \ldots \ldots$ & $\ldots$ A A . . & $\ldots . .$. & $\ldots$ \\
\hline B017CP1 & $\ldots$ T........ & $\ldots$ G.... & $\ldots s \ldots$ & $\cdots \cdots$ \\
\hline BO22 CP2 & $\ldots$ T........ & $\ldots$ G.... & $\cdots \cdots \cdots$ & $\ldots$ \\
\hline $\mathrm{BO} 30 \mathrm{CP}$ & $\ldots \mathrm{T} \ldots \ldots$ & $\ldots$ A $\ldots$ & $\cdots \cdots \cdots$ & $\cdots \cdots$ \\
\hline $\mathrm{BO} 34 \mathrm{CP}$ & $\ldots \mathrm{T} \ldots \ldots$ & $\ldots$ A $\ldots$ & $\cdots \cdots \cdots$ & $\cdots \cdots$ \\
\hline DL12CP1 & $\ldots \mathbf{T} \ldots \ldots$ & $\ldots$ G. . . & $\cdots \cdots \cdots$ & $\cdots \cdots$ \\
\hline DL24-CP & $\cdots \mathrm{E} \cdots \cdot$ & $\cdots$. $\cdots$ & $\cdots$. R & $\cdots \cdots$ \\
\hline $\mathrm{S} 2-\mathrm{CP} 2$ & $\cdots \mathbf{T} \ldots$ & A.... & $\cdots \cdots \cdots$ & $\cdots \cdots$ \\
\hline
\end{tabular}

Fig. 2. Multiple alignments of Bamboo mosaic virus (BaMV) coat protein (CP) N-terminal 35 amino acids. A, Multiple alignments of the N-terminal 35 amino acids of $\mathrm{CP}$ from the potexvirus group. MEGA 4 software was used to align the deduced polypeptide sequence. Identical residues are indicated by a dot $(\bullet)$, and gaps are indicated by a dash (-). The glycine-rich motif of BaMV CP is underlined. B, Comparison of the N-terminal amino acids of CP among $\mathrm{BaMV}$ isolates. Residues identical to those of the BaMV-S isolate (AF018156) are indicated by a dot (•) 
related to Foxtail mosaic virus (Yang et al. 1997), this GRM is unique to BaMV among potexvirus groups (Fig. 2A). No similar sequence has been found in the database. Furthermore, this GRM is highly conserved in BaMV isolates collected around the world (Fig. 2B).

\section{Mutational analysis of the $\mathrm{N} 35$ region}

in $N$. benthamiana protoplasts.

To determine the biological function of the N35 region of $\mathrm{CP}$ in planta, various mutations were introduced into the BaMV
$\mathrm{CP}$ region by deletion or site-directed mutagenesis (Fig. 3A). For CPstop, the start codon AUG was altered to stop codon UGA and disrupt CP translation. However, two other in-frame AUG codons in the CP ORF (Fig. 3B) could produce peptides with 157 and 47 amino acids in length, respectively (if these AUG sequences could function as start translation codons). The nucleotides at position -3 of these two putative translation initiation codons are pyrimidines $\mathrm{U}$ and $\mathrm{C}$ instead of a purine A or $\mathrm{G}$, respectively (Fig. 3B), which is not an optimal start codon context for protein translation (Kozak 1986, 2002). For
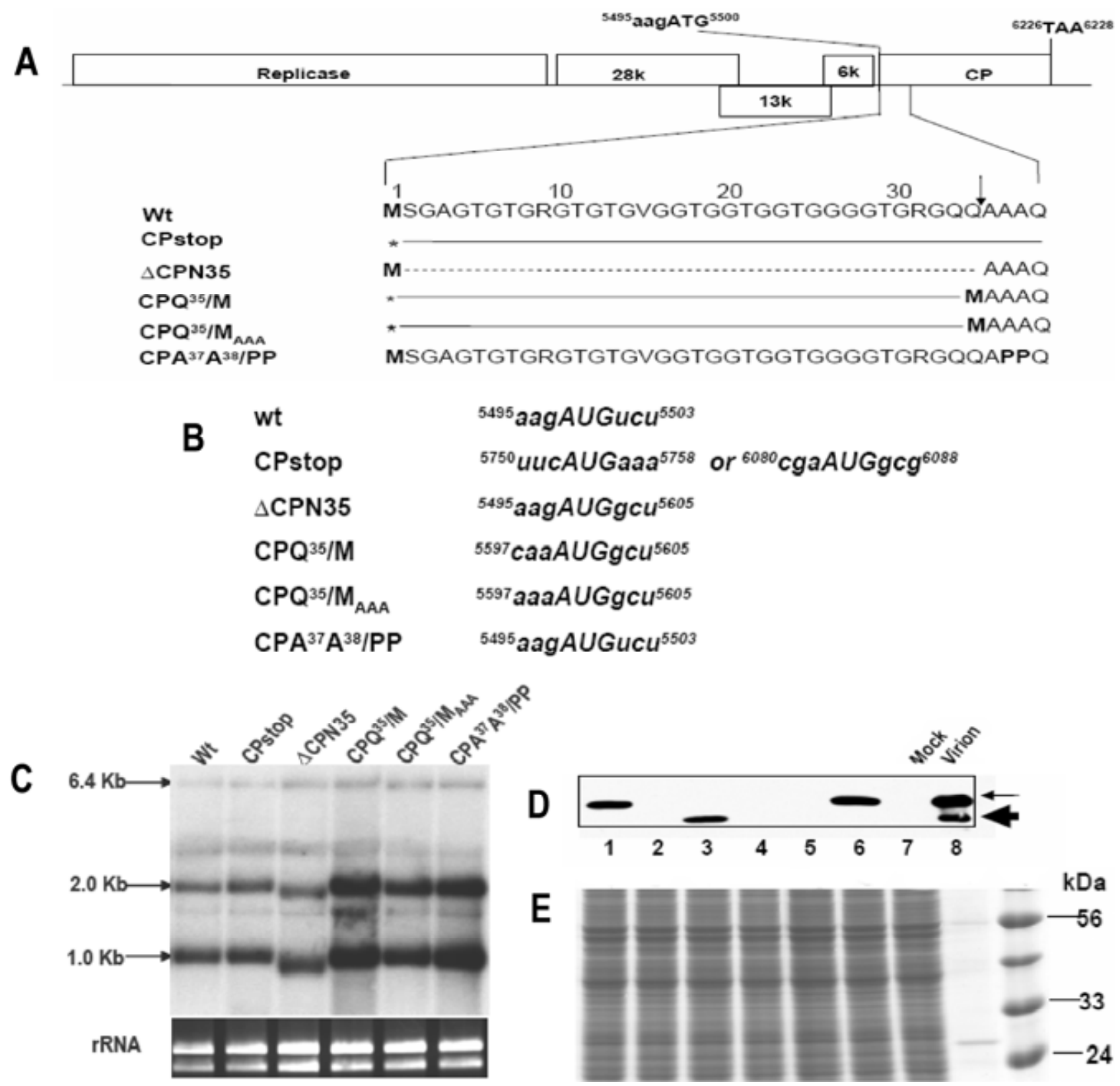

Fig. 3. Mutational analysis of the function of the N-terminal 35 amino acids of Bamboo mosaic virus (BaMV) coat protein (CP). A, Schematic representation of the structure of the wild type (wt) BaMV CP and derivatives. The genome of BaMV-S isolate (AF018156) contains five open reading frames. Nucleotide sequences corresponding to the CP start $\left({ }^{5495} \mathrm{aagATG}{ }^{5500}\right)$ and stop $\left({ }^{6226} \mathrm{TAA}^{6228}\right)$ codon regions are indicated. The N-terminal 39 amino acids encoded by the wt CP gene are shown. The arrow indicates where the truncated CP was formed. The solid lines of the mutants indicate that the N-terminal 35 amino acids were removed but the nucleotides were retained, and the line of dashes indicates that the nucleotides were removed. Asterisk indicates the stop codon. B, Nucleotide sequence in CP start regions of wt and derivatives of BaMV. C, Northern blot analysis of BaMV RNA accumulation in infected Nicotiana benthamiana protoplasts. $N$. benthamiana protoplasts were inoculated with in vitro transcripts from wt and mutants of BaMV at $24 \mathrm{~h}$ postinoculation (hpi). Total RNA extracted from approximately $1 \times 10^{4}$ protoplasts was loaded in each lane. The accumulation of BaMV RNA was measured using a BaMV-specific probe (Lin et al. 1996). Equal loading is shown as ethidium bromide staining. D and E, Sodium dodecyl sulfate-polyacrylamide gel electrophoresis and Western blot analysis of CP accumulation in $N$. benthamiana protoplasts at 24 hpi. D, Western blot analysis of BaMV CP accumulation measured from approximately $1 \times 10^{4}$ infected protoplasts by rabbit anti-BaMV CP. Purified BaMV virions (about $0.5 \mu \mathrm{g}$ ) were used as a positive control (lane 8 ). The thin arrow indicates the full-length CP, and the bold arrow indicates the truncated CP. E, Equal loading was shown as Coomassie Brilliant Blue G-250 staining. 
$\triangle \mathrm{CPN} 35$, nucleotides (from 5,501 to 5,602) encoding the second Ser to the 35 th Gln were deleted to produce a truncated $\mathrm{CP}$ lacking the $\mathrm{N} 35$ region. $\mathrm{CPQ}^{35} / \mathrm{M}$ was created on the basis of the CPstop and contains the additional substitution of the Gln codon CAA at amino acid 35 with the start codon AUG, to truncate the amino acid sequence from the second Ser to the 35 th Gln but retain the nucleotides. $\mathrm{CPQ}^{35} / \mathrm{M}_{\mathrm{AAA}}$ was created on the basis of $\mathrm{CPQ}^{35} / \mathrm{M}$ and contains an additional nucleotide substitution of pyrimidine $\mathrm{C}$ at position -3 of the created start codon AUG with a purine $\mathrm{A}$, to increase $\mathrm{CP}$ translation efficiency (Fig. 3B). For $\mathrm{CPA}^{37} \mathrm{~A}^{38} / \mathrm{PP}$, the $\mathrm{N}$-terminal 37 th and 38th Ala of wild-type (wt) CP were replaced by two prolines to prevent the truncation of the N35 region. Transcripts were synthesized in vitro from the wt and mutants and were inoculated into $N$. benthamiana protoplasts. Total RNA and protein was extracted and analyzed at $24 \mathrm{~h}$ postinfection (hpi).

Northern blotting showed that CPstop and $\triangle \mathrm{CPN} 35$ accumulated to near-wt levels, whereas $\mathrm{CPQ}^{35} / \mathrm{M}, \mathrm{CPQ}^{35} / \mathrm{M}_{\mathrm{AAA}}$, and $\mathrm{CPA}^{37} \mathrm{~A}^{38} / \mathrm{PP}$ accumulated to a slightly higher level in the infected protoplasts (Fig. 3C). These results suggest that all constructed mutants can replicate their genomic RNA at a singlecell level and indicate that the nucleotide sequence of the N35 region does not function as a cis-acting element mediating BaMV accumulation.

As expected, Western blot analysis with a specific antibody against BaMV $\mathrm{CP}$ revealed no $\mathrm{CP}$ in protoplasts infected with CPstop (Fig. 3D, lane 2), which suggests that either the other two AUG codons did not function as translation initiation codons or the translation efficiency is very low and the amount of protein was too low to be detected. Alternatively, the shorter peptide of CP is not stable. As shown in Figure 3D, protoplasts inoculated with $\triangle \mathrm{CPN} 35$ (lane 3) accumulated an amount of
$\mathrm{CP}$ nearly similar to that of the wt (lane 1) and $\mathrm{CPA}^{37} \mathrm{~A}^{38} / \mathrm{PP}$ (lane 6), based on the equal loading of each sample (Fig. 3E). Unexpectedly, no CP was detectable in protoplasts infected with $\mathrm{CPQ}^{35} / \mathrm{M}$ at $24 \mathrm{hpi}$ (lane 4). This finding may be due to low translation efficiency because the start codon context caaAUGgcu of mutant $\mathrm{CPQ}^{35} / \mathrm{M}$ (Fig. 3B) with the -3 position a pyrimidine $\mathrm{C}$ rather than a purine $\mathrm{A}$ or $\mathrm{G}$ is not a strong translation context according to the Kozak rule (Kozak 1986, 2002). To test this possibility, $\mathrm{CPQ}^{35} / \mathrm{M}_{\mathrm{AAA}}$ was generated from $\mathrm{CPQ}^{35} / \mathrm{M}$ by changing the pyrimidine $\mathrm{C}$ at the -3 position of the start codon context to a purine A, creating a strong start codon context (Fig. 3B). Still no CP was detectable in protoplasts infected with $\mathrm{CPQ}^{35} / \mathrm{M}_{\mathrm{AAA}}$ (Fig. 3D, lane 5). These results suggest that, in addition to the start codon context, the $5^{\prime}$ untranslated region (UTR) length or structure of the $\mathrm{CP}$ mutant may affect $\mathrm{CP}$ translation.

\section{Losing the N35 region causes chlorotic local lesions on $C$. quinoa plants.}

Although all of the tested mutants could replicate well in protoplasts independent of CP mutation (Fig. 3), the relationship between the biological relevance of the $\mathrm{N} 35$ region of BaMV CP in infectivity and symptom development remained to be determined in plants. As shown in Figure 4A, substantial necrotic local lesions were induced on $C$. quinoa leaves inoculated with wt BaMV at 8 days postinoculation (dpi), whereas blocking $\mathrm{CP}$ translation in CPstop resulted in no visible local lesions on $C$. quinoa leaves as were seen on mock-inoculated leaves. Lack of the $\mathrm{N} 35$ region in $\triangle \mathrm{CPN} 35$ and $\mathrm{CPQ}^{35} / \mathrm{M}_{\mathrm{AAA}}$ led to chlorotic rather than necrotic local lesions on $C$. quinoa leaves. At 8 dpi, only a few local lesions were induced on $C$. quinoa leaves by $\mathrm{CPQ}^{35} / \mathrm{M}$, which produced a lower level of $\mathrm{CP}$ (Fig. 4B, lane 3),

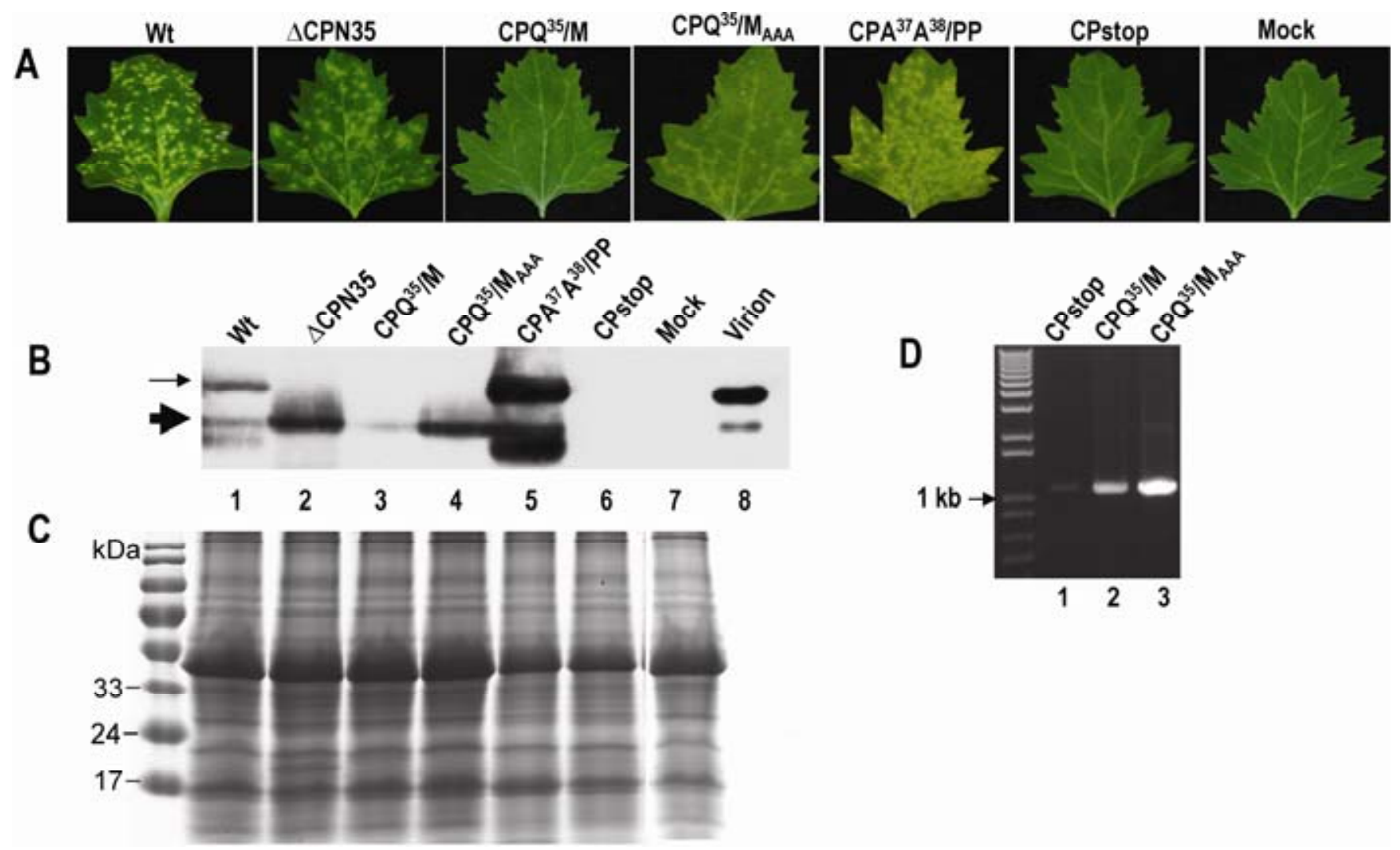

Fig. 4. Infectivity of wild type (Wt) and mutants of Bamboo mosaic virus (BaMV) on Chenopodium quinoa plants. A, Representative examples of symptoms induced by BaMV and BaMV mutants on inoculated leaves of $C$. quinoa. Photographs were taken at 8 days postinoculation. B and $\mathbf{C}$, Western blot analysis of coat protein (CP) accumulation. B, Western blot. Purified BaMV virions (about $0.5 \mu \mathrm{g}$ ) were used as a positive control. C, Equally loading is shown as Coomassie Brilliant Blue G-250 staining. D, Reverse transcription-polymerase chain reaction amplification of the CP gene. 
and the local lesion number did not increase with increased concentration of inoculum (from 0.1 to $1 \mu \mathrm{g}$ per leaf). In contrast, $\mathrm{CPQ}^{35} / \mathrm{M}_{\mathrm{AAA}}$ produced more $\mathrm{CP}$ product (Fig. $4 \mathrm{~B}$, lane 4 ) and induced more local lesion numbers. Surprisingly, inoculation of $\mathrm{CPA}^{37} \mathrm{~A}^{38} / \mathrm{PP}$ resulted in more severe local lesions than those of the wt and other mutants (Fig. 4A).

Western blot analysis revealed that $C$. quinoa leaves inoculated with wt BaMV accumulated full-length and truncated $\mathrm{CP}$ (Fig. 4B, lane 1). No CP was detected on C. quinoa leaves inoculated with CPstop (lane 6) as was found in $N$. benthamiana protoplasts, which indicates that CPstop is, indeed, a CP null mutant. $C$. quinoa leaves inoculated with $\triangle \mathrm{CPN} 35$ accumulated substantial CP (lane 2). At $8 \mathrm{dpi}$, faint $\mathrm{CP}$ was detected on $C$. quinoa leaves inoculated with $\mathrm{CPQ}^{35} / \mathrm{M}$ (lane 3 ), which suggests that its CP ORF is translatable but the translation efficiency is low. A significant amount of $\mathrm{CP}$ was produced on leaves inoculated with $\mathrm{CPQ}^{35} / \mathrm{M}_{\mathrm{AAA}}$, with strong translation context (lane 4). C. quinoa leaves inoculated with $\mathrm{CPA}^{37} \mathrm{~A}^{38} / \mathrm{PP}$ always showed a much higher $\mathrm{CP}$ level than that for the wt and other mutants (lane 5), which corresponded well with local lesion development.

To detect the BaMV RNA accumulation, total RNA was extracted from $C$. quinoa leaves inoculated with CPstop, $\mathrm{CPQ}^{35} / \mathrm{M}$, and $\mathrm{CPQ}^{35} / \mathrm{M}_{\mathrm{AAA}}$ at $8 \mathrm{dpi}$ for reverse transcriptionpolymerase chain reaction (RT-PCR) analysis. A trace amount of genomic RNA was detected on $C$. quinoa leaves inoculated with CPstop (Fig. 4D, lane 1), which indicates that CPstop could replicate in single cells but could not move cell to cell. In agreement with the local lesion development, substantial genomic RNA was detected on $C$. quinoa leaves inoculated with $\mathrm{CPQ}^{35} / \mathrm{M}$ (Fig. 4D, lane 2) and $\mathrm{CPQ}^{35} / \mathrm{M}_{\mathrm{AAA}}$ (Fig. 4D, lane 3).

To further examine whether these mutants are stable, PCR products were cloned into plasmid pGEMT-easy vector with TA cloning. Ten colonies for each mutant were chosen for sequencing. Sequencing results showed that the mutated sites were still maintained (data not shown), which suggests that the symptoms observed are indeed induced by the generated mutations.

\section{The $\mathbf{N} 35$ region is required for symptom formation} on $N$. benthamiana plants but is dispensable for BaMV long-distance movement.

The biological significance of the $\mathrm{N} 35$ region of BaMV CP in infectivity and symptom development was further examined in the systemic host $N$. benthamiana. No visible symptoms could be observed on mock- and CPstop-inoculated $N$. benthamiana leaves (Fig. 5). Unexpectedly, no visible symptoms other than slight yellowing on some leaves were induced on leaves inoculated with $\triangle \mathrm{CPN} 35, \mathrm{CPQ}^{35} / \mathrm{M}$, and $\mathrm{CPQ}^{35} / \mathrm{M}_{\mathrm{AAA}}$. Again, severe mosaic symptoms and yellowing were induced on leaves inoculated with $\mathrm{CPA}^{37} \mathrm{~A}^{38} / \mathrm{PP}$.

Northern blot analysis revealed that the wt and all mutants except CPstop induced BaMV genomic RNA accumulation on both inoculated and systemic $N$. benthamiana leaves (Fig. 6A), which indicates that all mutants except CPstop could mediate the cell-to-cell and long-distance movement of their RNA. Of note, much less genomic RNA was detected in leaves inoculated with $\mathrm{CPQ}^{35} / \mathrm{M}$ and $\mathrm{CPQ}^{35} / \mathrm{M}_{\mathrm{AAA}}$ (Fig. 6A, lanes 3 and 4) than in leaves inoculated with the wt BaMV and other mutants, except CPstop. This finding could be due to the relatively low $\mathrm{CP}$ level of the constructs, which resulted in less cell-to-cell movement than replication activity (Fig. 3). In agreement with the severity of symptoms, the highest level of genomic RNA was detected on both inoculated and systemic leaves inoculated with $\mathrm{CPA}^{37} \mathrm{~A}^{38} / \mathrm{PP}$ (Fig. 6A, lanes 5 and 12).

Western blot analysis revealed CP accumulated on both inoculated and systemic leaves inoculated with both wt and mutants, with the exception of CPstop (Fig. 6B). CP level was associated with genomic RNA level; that is, the CP level was the

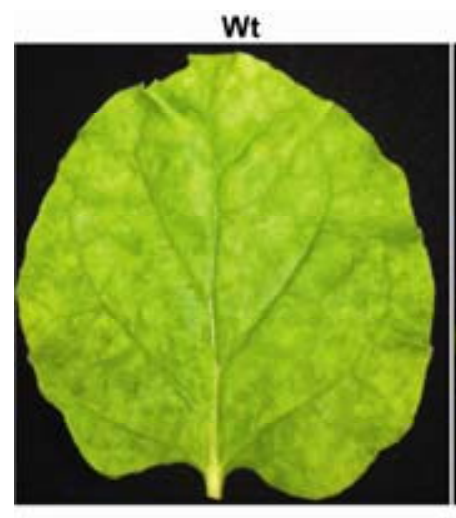

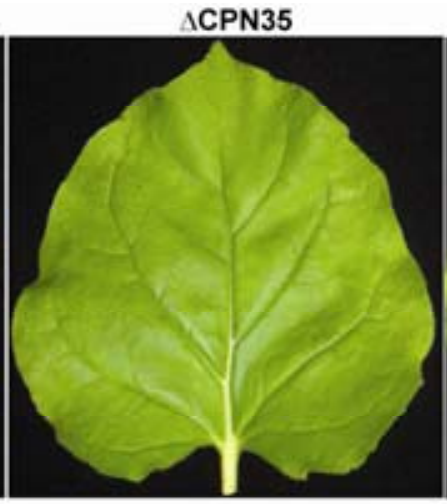

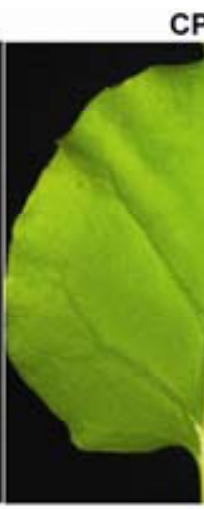

$\mathrm{CPQ}^{35} / \mathrm{M}$

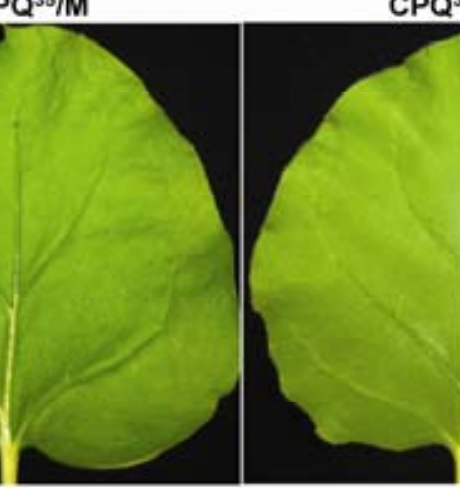

Mock

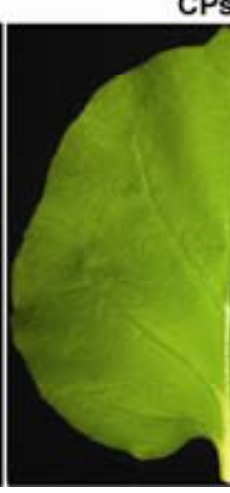

Pstop

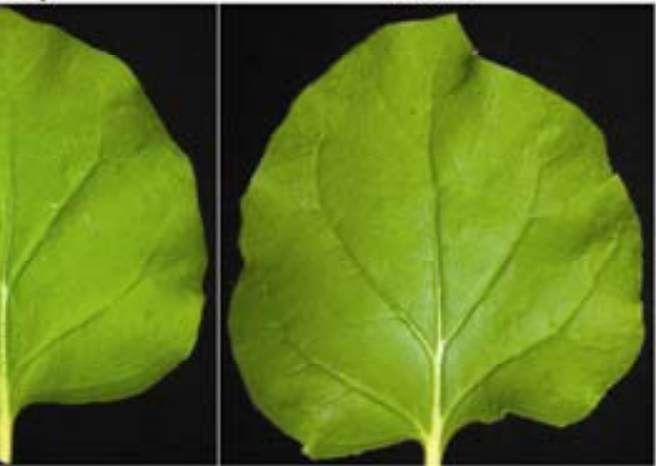

Fig. 5. Representative examples of symptoms induced by Bamboo mosaic virus (BaMV) and BaMV mutants on systemic leaves of Nicotiana benthamiana. Photographs were taken at 20 days postinoculation. 
highest and lowest on both inoculated and systemic leaves inoculated with $\mathrm{CPA}^{37} \mathrm{~A}^{38} / \mathrm{PP}$ (Fig. 6B, lanes 5 and 12) and $\mathrm{CPQ}^{35} / \mathrm{M}$ (Fig. 6B, lanes 3 and 10 ), respectively, according to the equal loading (Fig. 6C). The amount of $\mathrm{CP}$ was restored to a

Table 3. Summary of symptom expression and formation of particles of wild type (wt) Bamboo mosaic virus (BaMV) and derivatives

\begin{tabular}{lccllc}
\hline & \multicolumn{2}{c}{ Chenopodium quinoa } & & \multicolumn{2}{c}{ Nicotiana benthamiana } \\
\cline { 2 - 3 } Transcripts & Local lesions $^{\mathbf{a}}$ & Virions $^{\mathbf{b}}$ & & Symptoms $^{\mathbf{c}}$ & Virions $^{\mathbf{b}}$ \\
\hline $\mathrm{wt}$ & $>100$ & + & Mosaic & + \\
$\mathrm{CPstop}$ & - & - & - & - \\
$\Delta \mathrm{CPN} 35$ & $>100$ & + & Light yellowing & + \\
$\mathrm{CPQ}^{35} / \mathrm{M}$ & $<$ & - & - & + \\
$\mathrm{CPQ}^{35} / \mathrm{M}_{\mathrm{AAA}}$ & $<100$ & + & Mild mosaic & + \\
$\mathrm{CPA}^{37} \mathrm{~A}^{38} / \mathrm{PP}$ & $>100$ & + & Mosaic, yellowing & + \\
\hline
\end{tabular}

${ }^{a}$ The estimated number of local lesions on inoculated leaves at 8 days postinoculation. - indicates no visible local lesion.

${ }^{b}$ Formation of virions assayed by electron microscopy or serologically specific electron microscopy. + indicates virus particles were observed; indicates no virus particles observed.

${ }^{c}$ Typical symptoms induced on Nicotiana benthamiana by BaMV. - indicates no visible symptoms. significant level on both inoculated and systemic leaves inoculated with $\mathrm{CPQ}^{35} / \mathrm{M}_{\mathrm{AAA}}$ (Fig. 6B, lanes 4 and 11), although less than that with $\triangle \mathrm{CPN} 35$ (Fig. $6 \mathrm{~B}$, lanes 2 and 9). In addition, truncated $\mathrm{CP}$ was detected on systemic leaves inoculated with wt BaMV (Fig. 6B, lane 8) and $\mathrm{CPA}^{37} \mathrm{~A}^{38} / \mathrm{PP}$ (Fig. 6B, lane 12).

\section{N35 region is dispensable for BaMV virion formation.}

To test virion formation, crude sap of inoculated $C$. quinoa leaves and systemic $N$. benthamiana leaves was examined by negative staining or serologically specific electron microscopy (SSEM). As summarized in Table 3 , we observed virions on $C$. quinoa leaves inoculated with wt and all mutants except CPstop and $\mathrm{CPQ}^{35} / \mathrm{M}$ at $8 \mathrm{dpi}$. Similarly, virions were detected on the systemic $N$. benthamiana leaves inoculated with wt and all mutants except CPstop, at $20 \mathrm{dpi}$, which suggests that the $\mathrm{N} 35$ region is dispensable for virion assembly.

\section{DISCUSSION}

Previously, an N terminal-truncated CP of PVX and PMV was found from purified virions (Koenig et al. 1970, 1978; Zhang et al. 1993). However, the mechanism underlying the for-

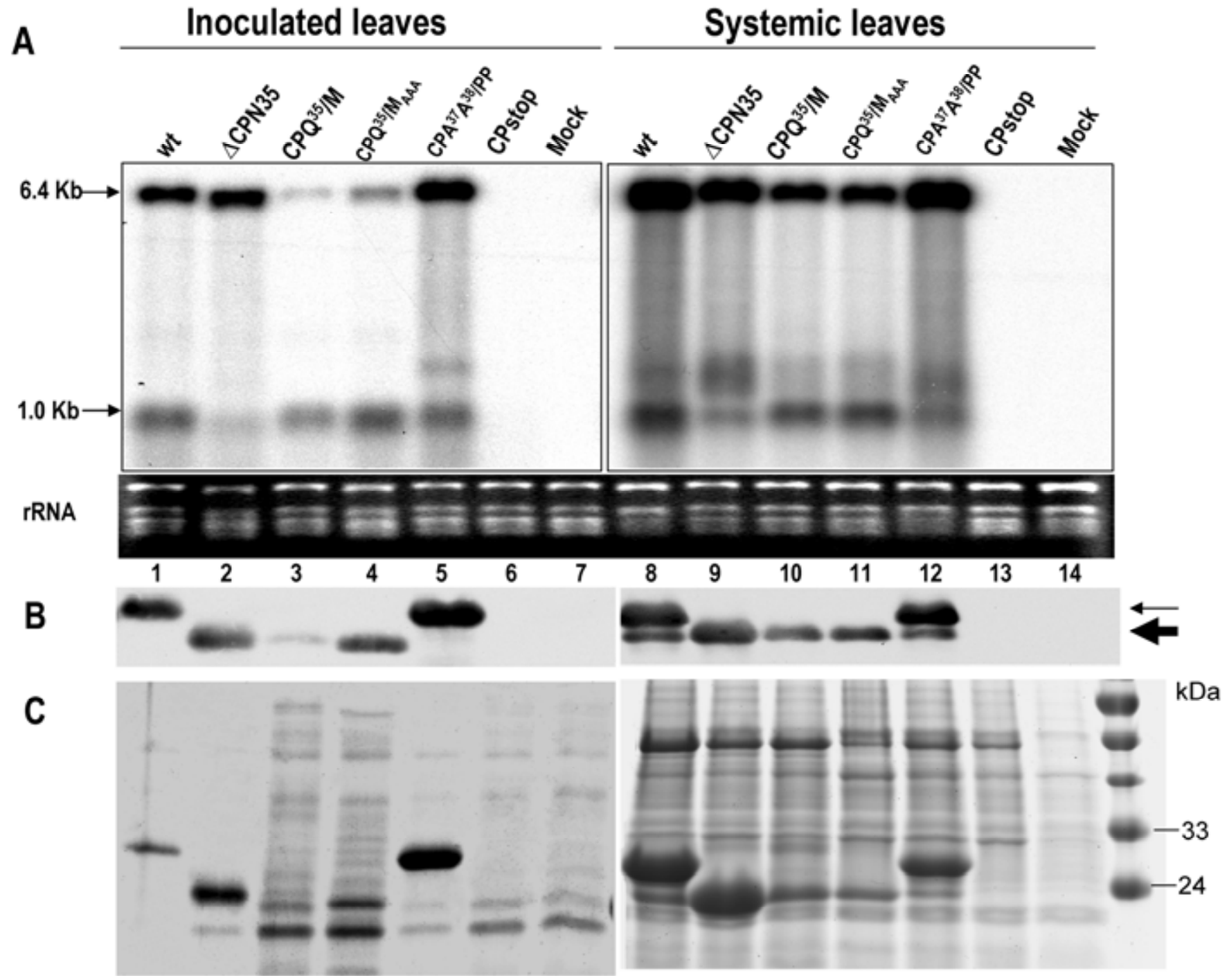

Fig. 6. Infectivity assays of wild type (wt) and mutants of Bamboo mosaic virus (BaMV) in Nicotiana benthamiana leaves. A, Northern blot analysis of BaMV RNA accumulation in $N$. benthamiana leaves inoculated with in vitro transcripts of wt and mutants of BaMV. Accumulation of BaMV RNA was assayed in inoculated leaves at 8 days postinoculation (dpi) and systemic leaves at 20 dpi. B and $\mathbf{C}$, Western blot analysis of coat protein (CP) accumulation in inoculated and systemic leaves of $N$. benthamiana. B, Western blot. The thin arrow indicates the full-length CP, and the bold arrow indicates the truncated CP. C, Equal loading was shown as Coomassie brilliant blue G-250 staining. 
mation of this truncated $\mathrm{CP}$ remains unclear, and its biological importance is unknown. In this work, we found a major truncated CP from both purified BaMV virions (Fig. 1A and B) and total proteins from different infected hosts (Figs. 1C, 4 and 6). Several lines of evidence suggest that the truncated BaMV CP from virions is not generated during the purification, and its formation is likely related to $\mathrm{CP}$ post-translational modifications. First, rCP did not have a tendency to form a truncated CP (Fig. $1 \mathrm{~A}$ and $\mathrm{B}$, lane 3 ), possibly because of lack of modifications. Second, multiple forms of CP were found on 2-D SDS-PAGE and were identified by MS/MS analysis (Fig. 1D; Table 2), which demonstrates that the BaMV CP may be modified. Although MS spectra did not reveal any modifications at the $\mathrm{N}$ terminus, some units of $\mathrm{CP}$ are phosphorylated at the $\mathrm{C}$ terminus (data not shown). In addition, the $\mathrm{N}$-terminal sequence of the full-length $\mathrm{CP}$ could not be obtained by $\mathrm{N}$-terminal sequencing, which further suggests that the $\mathrm{N}$ terminus may be blocked by unknown modification (Table 1). Motif scanning predicated five myristyl sites in this N35 region (MyHits Motif scan website). These modifications may result in substantial changes in physicochemical properties of the BaMV CP N terminus, leading to the easy truncation of the N35 region in a physical or chemical manner. Finally, although the same method was adopted in this study to extract the total protein from different materials, truncated $\mathrm{CP}$ was undetectable in BaMV-infected $N$. benthamiana protoplasts (Fig. 3D) and in inoculated $N$. benthamiana leaves (Fig. 6B), which suggests that the formation of the truncated $\mathrm{CP}$ is not due to the extraction process but is more related to one or both the specific tissues or hosts as well as the infection cycle. In addition, one more extensively truncated $\mathrm{CP}$ was observed in bamboo (Fig. 1C) and C. quinoa leaves (Fig. 4B) as well as purified virions (Fig.1 D, spot 6), which reflects the dynamic truncation of $\mathrm{CP}$ in vivo.

The N35 region of BaMV CP contains a conserved GRM (Fig. 2) with no significant homology with any known sequences to date. According to the recent proposal by Ozeki and associates (2009), the N35 region of BaMV CP belongs to the Nex region, with functions to be defined in potexvirus. Predicted results showed that this GRM-containing region could form a coiled-coil structure, which could mediate protein-protein interaction. Consistent with previous studies of other potexviruses (Chapman et al. 1992; Lico et al. 2006; Ozeki et al.2009), the $\mathrm{N} 35$ region is not required for BaMV replication (Figs. 3C and 6A), virus assembly (Table 3), cell-to-cell movement (Figs. 4 and 6), or long-distance movement (Figs. 5 and 6). Furthermore, mutational analysis confirmed that the nucleotide sequence of the N35 region of BaMV CP does not function as a cis-regulatory element for BaMV replication (Fig. 3C). Because potexvirus $\mathrm{CP}$ has distinct functions in cell-to-cell and systemic movement (Lico et al. 2006), the potexvirus is generally believed to move from cell to cell via the interaction of host proteins and the ribonucleoproteic complex (RNP), which is composed of viral RNA, CP, and TGBp1 (Verchot-Lubicz et al 2007). Because the mutant $\triangle \mathrm{CPN} 35$ could still move from cell to cell (Figs. 4, 5, and 6), it is suggested that the N35 region does not affect RNP formation or the interaction of host proteins and RNP. In contrast, the long-distance movement of potexvirus is mediated by assembled virus particles through phloem (Verchot-Lubicz et al 2007). Our findings that deletion of the N35 region did not block virion formation and systemic movement also support the idea that long-distance movement of BaMV mutants was mediated by assembled virus particles through phloem. This result also indicates that the mutated virus particles could still interact with host proteins to load into and unload its virus from phloem. The truncated CP may still exert the two main functions, cell-tocell movement and virus assembly, because of the high stability of dimers both from full-length and truncated BaMV CP, even under highly denaturing conditions (Fig. 1). Previous studies suggested that dimer formation of CP may be a prerequisite for its function (Krol et al. 1999; Tenllado and Bol 2000). The Cterminal mutations rather than other $\mathrm{N}$-terminal mutations of Alfalfa mosaic virus $\mathrm{CP}$ can affect dimer formation, thus leading to no virion assembly (Choi and Loesch-Fries 1999). Collectively, the data suggest that the $\mathrm{C}$ terminus of BaMV CP may be involved in dimer formation.

One common response of plants to virus invasion is developmental defects resulting in symptom expression. Symptoms are the result of perturbance and interference in the regulation of genes involved in plant growth and development (Revers et al. 1999). The role of viral CP in symptom expression has been reported in several viruses (Banerjee et al. 1995; Bol 2005; Culver and Dawson 1989; Knorr and Dawson 1988; Neelman et al. 1991; Shintaku and Palukaitis1992). Some CP themselves act as an elicitor inducing a hypersensitive reaction (HR) in specific hosts. For example, Tobacco mosaic virus $\mathrm{CP} 25$ is an elicitor molecule responsible for the induction of $\mathrm{HR}$ in Nicotiana sylvestris (Culver and Dawson 1989). The CP of tobamoviruses, including Paprika mild mottle virus and Pepper mild mottle virus, are the elicitor of the capsicum L(2) and L(4) gene-mediated HR (Gilardi et al. 2004). In the potexviruses, PVX CP has been reported to be a strain-specific elicitor of Rx1-mediated virus resistance in potato (Bendahmane et al. 1995). In some cases, one amino-acid change of CP results in different symptom expression. For instance, the amino-acid residue at position 151 of the $\mathrm{CP}$ of Cowpea chlorotic mottle virus (CCMV) determines the symptom phenotype of strains CCMV-T and CCMV-M on cowpea (de Assis Filho et al. 2002). Similarly, a single amino-acid substitution in the CP of Cucumber mosaic virus induces chlorosis in tobacco (Shintaku and Palukaitis 1992). However, few reports of the N-terminal region of potexvirus $\mathrm{CP}$, especially the Nex, in symptom expression are available. Our studies clearly support that the Nex of BaMV CP is a symptom determinant in C. quinoa and $N$. benthamiana. How the $\mathrm{N} 35$ region interacts with the hosts leading to the misregulation of genes involved in the symptom expression should be explored.

Because the N35 region of BaMV plays an important role in symptom expression and is easy to be truncated in vivo, we attempted to explore the consequence of preventing the N35 region truncation by generating $\mathrm{CPA}^{37} \mathrm{~A}^{38} / \mathrm{PP}$. Presumably, the truncated $\mathrm{CP}$ was formed by an unknown proteinase, as was previously suggested (Koenig et al. 1978). The putative enzyme that could cleave the peptide bond between amino acids Gln and Ala at positions 35 and 36 of BaMV CP was predicted to be thermolysin (EC 3.4.24.27) by the ExPaSy PeptideCutter program. The enzyme is a thermostable neutral metalloproteinase produced by the gram-positive bacteria Bacillus thermoproteolyticus (Endo 1962) and specifically catalyzes the hydrolysis of peptide bonds containing hydrophobic amino acids. The cleavage should be blocked in the mutant $\mathrm{CPA}^{37} \mathrm{~A}^{38} / \mathrm{PP}$ with the 37 th and 38th Ala of CP replaced by Pro (Keil 1992). Although such mutation did not totally block the formation of truncated $\mathrm{CP}$ (Figs. 4B, lane 5 and 6B, lane 12), the mutant showed higher accumulation of full-length $\mathrm{CP}$ and stronger symptom development than did the wt BaMV, which further confirms our conclusion that the N35 containing the conserved GRM of BaMV CP is required for symptom formation.

\section{MATERIALS AND METHODS}

Constructs of BaMV cDNA mutants for infectivity assay.

Plasmid pBS2-8, harboring a full-length cDNA of BaMV isolate $\mathrm{S}$ (BaMV-S, EMBL/GenBank accession number AF018156) with a T7 promoter fused upstream of the 5' UTR 
and a poly (A) tail downstream of the $3^{\prime}$ UTR, was constructed by inserting the full-length cDNA of BaMV-S into plasmid pUC119 with restriction enzymes XbaI and SacI (Lin et al. 2004). Plasmid pBS2-8 hereafter is called wt BaMV cDNA and, unless otherwise indicated, was used as the template to generate the deleted or site-directed cDNA mutants by standard molecular methods (Sambrook et al. 2000).

To create the cDNA mutant with the CP translation disruption, we generated a cDNA mutant, CPstop. The first fragment was generated from pBS2-8 with primers CP1f (5'-CACTAT GCATCATTCTGTCCATAC-3'), corresponding to nucleotides 5,314 to 5,337 of BaMV-S (this was also applied to other primers unless indicated), and CPstopr (5'-AGCTCCAGAtca CTTTAGTG-3'; the position of start codon AUG of the CP ORF is underlined and was replaced by the stop codon UGA, denoted as lowercase letters), corresponding to nucleotides 5,490 to 5,509. Similarly, the second fragment was synthesized with primers CPstopf (5'-CACTAAAGtgaTCTGGAGCT- $\left.3^{\prime}\right)$, corresponding to nucleotides 5,490 to 5,509, and CP4r (5'-CC CAGTCACGACGTTGTAAAA-3'), corresponding to nucleotides 302 to 322 of pUC119. Next, overlapping PCR was performed to link the first and second fragments with the primer pair CP1f and CP4r, with the mixture of the first and second fragments used as the PCR template. After mutagenesis, the final PCR product was digested with $N s i \mathrm{I}$ and $\mathrm{SacI}$ and was subcloned into pBS2-8 digested with the same set of restriction enzymes to replace the corresponding fragment of wt cDNA. The same strategy was applied to construct the other cDNA mutants with their respective primers.

For $\triangle \mathrm{CPN} 35$, the primer pair $\triangle \mathrm{CPN} 35 \mathrm{r}\left(5^{\prime}\right.$-TCCCAGGG CTGGGCTGCAGCCATCTTTAGTGTTTAATTTA-3'), corresponding to nucleotides 5,481 to 5,500 and 5,603 to 5,622 , was used instead of CPstopr, and $\triangle \mathrm{CPN} 35 \mathrm{f}$ (5'-TAAATTAAA CACTAAAGATGGCTGCAGCCCAGCCCTGGGA-3') complementary to $\triangle \mathrm{CPN} 35 \mathrm{r}$ was used instead of CPstopf.

$\mathrm{CPQ}^{35} / \mathrm{M}$ was created, with CPstop instead of pBS2-8 used as the PCR template with the primers $\mathrm{CPQ}^{35} / \mathrm{Mr}\left(5^{\prime}\right.$-GCTGCA GCcatTTGCCCTCTA-3'; the position of the created codon AUG is underlined, and lowercase letters indicate the mutated nucleotides), corresponding to nucleotides 5,590 to 5,610, and $\mathrm{CPQ}^{35} / \mathrm{Mf}$ (5'-TAGAGGGCAAatgGCTGCAGC-3'), complementary to $\mathrm{CPQ}^{35} / \mathrm{Mr}$.

$\mathrm{CPQ}^{35} / \mathrm{M}_{\mathrm{AAA}}$ was constructed with $\mathrm{CPQ}^{35} / \mathrm{M}$ used as the PCR template with the primers $\mathrm{CPQ}^{35} / \mathrm{M}_{\mathrm{AAA}} \mathrm{r}$ (5'-GCTGCAGC cat $\mathrm{T}$ TtCCCTCTA-3'; lowercase letters indicate the mutated nucleotides), corresponding to nucleotides 5,590 to 5,610 , and $\mathrm{CPQ}^{35}$ /

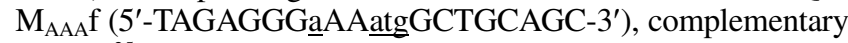
to $\mathrm{CPQ}^{35} / \mathrm{M}_{\mathrm{AAA}} \mathrm{r}$.

$\mathrm{CPA}^{37} \mathrm{~A}^{38} / \mathrm{PP}$ was constructed with $\mathrm{pBS} 2-8$ used as the PCR template with the primers $\mathrm{CPA}^{37} \mathrm{~A}^{38} / \mathrm{PPr}\left(5^{\prime}\right.$-AGGGCTGtggtgg AGCTTGTTGCCCTCTA-3'; lowercase letters indicate the mutated nucleotides), corresponding to nucleotides 5,590 to 5,618, and $\mathrm{CPA}^{37} \mathrm{~A}^{38} / \mathrm{PPf}$ (5'-TAGAGGGCAACAAGCTccacca CAGCCCT-3'). All the final constructs were confirmed by DNA sequencing.

\section{Construct used for overexpressing recombinant $\mathrm{CP}$ in Escherichia coli.}

The CP ORF was generated from plasmid pBS2-8 by PCR with the primers CPndeIf (5'-CTAcatATgTCTggAgCTggAAC gggAA-3'; the underlined indicates the NdeI site) and CPxhoIr (5'-ATgCTCgAgTTAgTCTgATgTTggTTCgggA-3'; the underlined indicates the XhoI site). The PCR product was digested with NdeI and XhoI and cloned into plasmid pET21b (Novagen, Madison, WI, U.S.A.) restricted with the same set of enzymes. The final plasmid was confirmed by sequencing and named pET21CP.
In vitro capped RNA synthesis and inoculation.

In vitro capped RNA synthesis was performed mainly as described (Lin et al. 2004). Briefly, plasmids were linearized at the $3^{\prime}$ end of the poly (A) tail with the restriction enzyme SacI and were purified twice with phenol/chloroform/isoamyl alcohol (25:24:1). Capped RNA was synthesized with a linearized plasmid directed by a $\mathrm{T} 7$ promoter in the presence of $\mathrm{m}^{7} \mathrm{GpppG}$.

For whole-plant inoculation, true leaves of one-month-old C. quinoa or $N$. benthamiana plants were inoculated with wt or various mutant transcripts with about $0.1 \mu \mathrm{g}$ of transcript per leaf. For inoculating protoplasts, approximately $2 \times 10^{5}$ protoplasts isolated from $N$. benthamiana suspension cells were transfected with about $1 \mu \mathrm{g}$ of transcripts by electroporation as described previously (Lin et al. 1992).

\section{RT-PCR and northern blot analysis.}

Total RNA was extracted from infected protoplasts, inoculated leaves, and systemic leaves. For RT-PCR, $1 \mu \mathrm{g}$ of DNAfree total RNA was used to synthesize cDNA by the SuperScript III first-strand synthesis system (Invitrogen, Carlsbad, CA, U.S.A.) according to the procedure provided. cDNA (diluted 10-fold) was used as a PCR template with the primers CP1f and CPRTr (5'-TTCGAGCTCTGGAAAAAACTGTAG AAACC-3'; the underlined indicates the SacI site) corresponding to nucleotides 6,347 to 6,366 . PCR conditions were $94^{\circ} \mathrm{C}$ for $5 \mathrm{~min}$, then 35 cycles of $94^{\circ} \mathrm{C}$ for $30 \mathrm{~s}, 60^{\circ} \mathrm{C}$ for $30 \mathrm{~s}$, $72^{\circ} \mathrm{C}$ for $1 \mathrm{~min}$, and a final extension at $72^{\circ} \mathrm{C}$ for $7 \mathrm{~min}$. The PCR product was first checked by loading for $1 \%$ Tris-borateEDTA agarose gel and was then cloned into pGEMT-easy vector and sequenced. For Northern blot analysis, total RNA was denatured by glyoxation before the separation; a ${ }^{32} \mathrm{P}$ labeled $\mathrm{BaMV}$-specific probe corresponding to the $\mathrm{CP}$ region and $3^{\prime}$ UTR was used to measure genomic and subgenomic plus-strand RNA (Lin et al. 1996).

\section{Virion purification and $\mathrm{CP}$ isolation.}

Virions were purified as described previously (Lin and Chen 1991; Lin et al. 1992) from infected $N$. benthamiana plants. $\mathrm{CP}$ was further isolated from purified virion by the phenol method as described (Peck et al. 2001).

\section{Protein analysis.}

For N-terminal protein sequencing, purified BaMV virions derived from infected leaves of $C$. quinoa or $N$. benthamiana were denatured by heating to $100^{\circ} \mathrm{C}$ in a water bath and were separated on $12 \%$ SDS-PAGE. Proteins were then transferred onto polyvinylidene difluoride (PVDF) membrane (Millipore, Bedford, MA, U.S.A.). Membranes were stained with Ponceau $\mathrm{S}$ staining solution for 1 to $3 \mathrm{~min}$, and bands corresponding to the monomer or dimer of $\mathrm{BaMV} \mathrm{CP}$ or truncated $\mathrm{CP}$ were excised and extensively washed with sterile Milli-Q water. Membrane pieces were sequenced by use of an Applied Biosystems Procise-cLC Protein Sequencer at the Core Facilities for Proteomics and Structural Biology Research (CFPSBR, Institute of Biological Chemistry, Academia Sinica, Taipei, Taiwan).

For 1-D SDS-PAGE assay, an equal volume of $2 \times$ Laemmli buffer (100 mM Tris-Cl, pH 6.8, 4\% SDS, 20\% glycerol, $0.2 \%$ bromophenol blue, $200 \mathrm{mM}$ DTT or $\beta$-mercaptoethanol) was added to the purified BaMV virions. The sample was boiled in a $100^{\circ} \mathrm{C}$ water bath for $5 \mathrm{~min}$, and $\mathrm{CP}$ was separated on $12 \%$ SDS-PAGE. Total proteins from infected leaves of bamboo (Bambusa vulgaris McClure), C. quinoa, or N. benthamiana were extracted directly in $2 \times$ Laemmli buffer. Briefly, about $0.1 \mathrm{~g}$ of freshly infected leaves was ground in liquid nitrogen with use of a mortar and pestle. Then, the powders were trans- 
ferred into 1.5-ml pre-chilled Eppendorf tubes and $100 \mu \mathrm{l}$ of $2 \times$ Laemmli buffer was added. After a brief vortexing, protein samples were denatured immediately by boiling them in a $100^{\circ} \mathrm{C}$ water bath for $5 \mathrm{~min}$ and were electrophoresed through a Tris-glycine system. The 1-D gel was stained with PageBlueProtein staining solution (Fermentas, Vilnius, Lithuania). Protein bands of interest were excised from the gel and were digested with trypsin (Promega, Madison, WI, U.S.A.) and analyzed by matrix-assisted laser desorption ionization-time of flight-based mass spectrometry (MALDI-TOF) at the CFPSBR or by LTQ nanoLC-nanoESI-MS/MS at the Proteomics Core Lab (Institute of Plant and Microbial Biology/Agricultural Biotechnology Research Center, Academia Sinica).

For Western blot analysis, proteins were blotted onto PVDF membrane and were probed with a polyclonal antibody specific to the BaMV CP (anti-BaMV CP) (Lin and Chen 1991) at 1:5,000 and then with peroxidase-labeled goat anti-rabbit antibody (Sigma, St. Louis) at 1:10,000. Signals were visualized using the Enhanced Chemiluminescence Plus kit (Millipore).

For the 2-D electrophoresis assay, dried CP powder, isolated from freshly purified virions by the phenol method as described by Peck and associates (2001), was dissolved directly in rehydration buffer containing $8 \mathrm{M}$ urea, 2\% CHAPS, $40 \mathrm{mM}$ DTT, $0.5 \% 3-10 \mathrm{NL}$ strip buffer, and $0.002 \%$ (wt/vol) bromophenol blue and was incubated at room temperature for $1 \mathrm{~h}$. Protein concentration was determined by use of the Bio-Rad Rc Dc protein assay kit (BioRad, Hercules, CA, U.S.A.). About $50 \mu \mathrm{g}$ of $\mathrm{CP}$ in $350 \mu \mathrm{l}$ of rehydration buffer was loaded for rehydration on the $18-\mathrm{cm}$, nonlinear, $\mathrm{pH} 3$ to 10 , immobilized $\mathrm{pH}$ gradient strip of the IPGphor unit (GE Healthcare, Pisctaway, NJ, U.S.A.). The conditions of isofocusing and 2-D gel electrophoresis are available upon request. In brief, the rapid ramp condition for isofocusing was $100 \mathrm{Kv}$ per $\mathrm{h}$. The strips were equilibrated in a solution of $6 \mathrm{M}$ urea, $50 \mathrm{mM}$ Tris- $\mathrm{HCl}(\mathrm{pH} 8.8)$, $2 \%$ SDS, $30 \%$ glycerol, $1 \%(\mathrm{wt} / \mathrm{vol})$ DTT, and $0.002 \%$ (wt/vol) bromophenol blue for $15 \mathrm{~min}$ and were then placed into the same solution, except that DTT was replaced with $2.5 \%(\mathrm{wt} / \mathrm{vol})$ iodoacetamide for another $15 \mathrm{~min}$. Next, the strips were placed onto $12.5 \%$ SDS-polyacrylamide gel sealed by a $1 \%$ low-melting-point (LMP) agarose solution containing $1 \%$ LMP agarose, $25 \mathrm{mM}$ Tris base, $192 \mathrm{mM}$ glycine, $0.1 \%$ SDS, and $0.002 \%$ (wt/vol) bromophenol blue. Electrophoresis was subsequently performed. The 2-D gels were stained with PageBlue protein-staining solution. Protein spots of interest were excised from the gel and were digested with trypsin (Promega) and analyzed by MALDI-TOF or Thermo Finnegan ProteomeX LTQ nanoLC-nano ESI-MS/MS as mentioned above.

For rCP expression and purification, pET21CP was transformed into the BL21 (DE3) strain of E. coli. A 5-ml overnight bacterial culture was inoculated in $500 \mathrm{ml}$ of Luria Broth and was grown at $37^{\circ} \mathrm{C}$. With an optical density at $600 \mathrm{~nm}$ of about 0.5 to 0.6 , isopropyl- $\beta$-D-thiogalactopyranoside was added to a final concentration of $1.0 \mathrm{mM}$, and the cells were grown for a further $16 \mathrm{~h}$ at $25^{\circ} \mathrm{C}$. Bacteria were collected by centrifugation at $4,000 \times g$ for $20 \mathrm{~min}$ and were frozen at $-70^{\circ} \mathrm{C}$ for further assays or were resuspended in lysis buffer $(50 \mathrm{mM}$ Tris- $\mathrm{HCl}$, $\mathrm{pH}$ 8.0, $1 \mathrm{mM}$ EDTA, $10 \mathrm{mM}$ DTT, $1 \mathrm{mM}$ phenylmethylsulfonyl fluoride, and $1 \times$ protease inhibitor cocktail) with $5 \mathrm{ml}$ of lysis buffer per gram of pellet. The cells were then disrupted with sonication on ice and underwent centrifugation at 12,000 rpm for $30 \mathrm{~min}$ at $4^{\circ} \mathrm{C}$. The supernatants were saved for further protein purification by loading onto a Macro-Prep DEAE Cartridge (BioRad) after passing through a $0.45-\mu \mathrm{m}$ filter. The fractions containing $\mathrm{rCP}$ were pooled and concentrated to $1 \mathrm{ml}$ by Amicon Ultra-10 devices (Millipore) before being loaded onto a Sephacryl S-200 column (Hiprep 16/60, GE Healthcare) for further purification. Proteins were eluted by buffer $\mathrm{S}$ (50 $\mathrm{mM}$ Tris-HCl, $\mathrm{pH} 8.0,150 \mathrm{mM} \mathrm{NaCl}, 1 \mathrm{mM}$ EDTA, and 5 $\mathrm{mM}$ DTT), and the fractions of $\mathrm{rCP}$ were pooled and stored at $-70^{\circ} \mathrm{C}$ in buffer $\mathrm{S}$ containing $50 \%$ glycerol.

\section{Electron microscopy or SSEM.}

For negative staining, crude sap from fresh leaves of $C$. quinoa at $8 \mathrm{dpi}$ or systemic leaves of $N$. benthamiana at $20 \mathrm{dpi}$ were collected and dropped on glow-discharged carbon-coated copper grids. Grids were washed twice with Milli-Q water, were stained with $2 \%$ uranyl acetate, and were then air-dried and examined on transmission electron microscopy (Philips CM 100 Bio) under $80 \mathrm{KV}$. For SSEM, similar procedures were adopted, except that the copper grids were precoated with rabbit anti-BaMV virion serum at 1:100 before the crude sap was dropped on the grids.

\section{ACKNOWLEDGMENTS}

We thank J.-T. Wu, H.-T. Yang, and H.-C. Chen for technical assistance, and M.-Z. Fang for sequencing and assistance from Proteomics Core Lab (Institute of Plant and Microbial Biology, Academia Sinica). This research was supported by grants from the National Science Council (NSC962313-B-001-011) and from Academia Sinica, Taipei, Taiwan.

\section{LITERATURE CITED}

Abouhaidar, M. G., and Lai, R. 1989. Nucleotide sequence of the 3 '-terminal region of Clover yellow mosaic virus RNA. J. Gen. Virol. 70:1871-1875.

Banerjee, N., Wang, J. Y., and Zaitlin, M. 1995. A single nucleotide change in the coat protein gene of Tobacco mosaic virus is involved in the induction of severe chlorosis. Virology 207:234-239.

Bendahmane, A., Köhn, B.A., Dedi, C., Baulcombe, D.C. 1995. The coat protein of potato virus $\mathrm{X}$ is a strain-specific elicitor of Rx1-mediated virus resistance in potato. Plant J. 8:933-41.

Bol, J. F. 2005. Replication of alfamo- and ilarviruses: Role of the coat protein. Annu. Rev. Phytopathol. 43:39-62.

Chapman, S., Hills, G., Watts, J., and Baulcombe, D. C. 1992. Mutational analysis of the coat protein gene of Potato virus X: Effects on virion morphology and viral pathogenicity. Virology 191:223-230.

Choi, J., and Loesch-Fries, L. S. 1999. Effect of C-terminal mutations of Alfalfa mosaic virus coat protein on dimer formation and assembly in vitro. Virology 260 (1):182-189.

Culver, J. N., and Dawson, W. O. 1989. Point mutations in the coat protein gene of the Tobacco mosaic virus induce hypersensitivity in Nicotiana sylvestris. Mol. Plant Microbe Interact. 2:209-213.

de Assis Filho, F. M., Paguio, O. R., Sherwood , J. L., and Deom, C. M. 2002 . Symptom induction by Cowpea chlorotic mottle virus on Vigna unguiculata is determined by amino acid residue 151 in the coat protein. J. Gen. Virol. 83(Pt 4):879-883.

Endo, S. 1962. Studies on protease produced by thermophilic bacteria. J. Ferment. Technol. 40:346-353.

Gilardi, P., García-Luque, I., and Serra, M. T. 2004. The coat protein of tobamovirus acts as elicitor of both L2 and L4 gene-mediated resistance in Capsicum. J. Gen. Virol. 85:2077-2085.

Goulden, M. G., and Baulcombe, D. C. 1993. Functionally homologous host components recognize Potato Virus $X$ in Gomphrena globosa and potato. Plant Cell 5:921-930.

Huang, Y. L., Hsu, Y. H., Han, Y. T., Meng, M. 2005. mRNA guanylation catalyzed by the S-adenosylmethionine-dependent guanylyltransferase of Bamboo mosaic virus. J. Biol. Chem. 280:13153-13162.

Keil, B. 1992. Page 335 in: Specificity of Proteolysis. Springer-Verlag Berlin-Heidelberg-NewYork.

Knorr, D. A., and Dawson, W. O. 1988. A point mutation in the Tobacco mosaic virus capsid protein gene induces hypersensitivity in Nicotiana sylvestris. Proc. Natl. Acad. Sci. U.S.A. 85:170-174.

Kozak, M. 1986. Bifunctional RNAs in eukaryotes. Cell 87:481-483.

Kozak, M. 2002. Pushing the limits of the scanning mechanism for initiation of translation. Gene 299:1-34.

Koenig, R., and Torrance, L. 1986. Antigenic analysis of Potato virus X by means of monoclonal antibodies. J. Gen. Virol. 67:2145-2151.

Koenig, R., Stegemann, M. E., Francksen, H., and Paul, H. L. 1970. Protein subunits in Potato virus $X$ group. Determination of the molecular weights by polyacrylamide electrophoresis. Biochem. Biophys. Acta 207:184-189. 
Koenig, R., Tremaine, J. H., and Shepard, J. F. 1978. In situ degradation of the protein chain of Potato virus $X$ at the N- and C-termini. J. Gen. Virol. 38:329-337.

Krol, M. A., Olson, N. H., Tate, J., Johnson, J. E., Baker, T. S., and Ahlquist, P. 1999. RNA-controlled polymorphism in the in vivo assembly of 180-subunit and 120-subunit virions from a single capsid protein. Proc. Natl. Acad. Sci. U.S.A. 96(24):13650-13655.

Li, Y. I., Chen, Y. J., Hsu, Y. H., and Meng, M. 2001a. Characterization of the AdoMet-dependent guanylyltransferase activity that is associated with the $\mathrm{N}$ terminus of Bamboo mosaic virus replicase. J. Virol. 75:782-788.

Li, Y. I., Shih, T. W., Hsu, Y. H., Han, Y. T., Huang, Y. L., and Meng, M. 2001b. The helicase-like domain of plant potexvirus replicase participates in formation of RNA 5' cap structure by exhibiting RNA 5'triphosphatase activity. J. Virol. 75:12114-121120.

Lico, C., Capuano, F., Renzone, G., Donini, M., Marusic, C., Scaloni, A., Benvenuto, E., and Baschieri, S. 2006. Peptide display on Potato virus $X$ : Molecular features of the coat protein-fused peptide affecting cell-tocell and phloem movement of chimeric virus particles. J. Gen. Virol. 87(Pt 10):3103-3112.

Lin, M. K., Chang, B. Y., Liao, J. T., Lin, N. S., and Hsu, Y. H. 2004. Arg16 and Arg-21 in the N-terminal region of the triple-gene-block protein 1 of Bamboo mosaic virus are essential for virus movement. J. Gen. Virol. 85:251-259.

Lin, N. S., and Chen, C. C. 1991. Association of Bamboo mosaic virus (BaMV) and BaMV-specific electron-dense crystalline bodies with chloroplasts. Phytopathology 81:1551-1555.

Lin, N. S., and Hsu, Y. H. 1994. A satellite RNA associated with Bamboo mosaic potexvirus. Virology 202:707-714.

Lin, N. S., Huang, T. Z., and Hsu, Y. H. 1992. Infection of barely protoplasts with bamboo mosaic virus RNA. Bot. Bull. Acad. Sin. 33:271275

Lin, N. S., Lin, B. Y., Lo, N. W., Hu, C. C., Chow, T. Y., and Hsu, Y. H. 1994. Nucleotide sequence of the genomic RNA of Bamboo mosaic potexvirus. J. Gen. Virol. 75:2513-2518.

Lin, N. S., Lee, Y. S., Lin, B. Y., Lee, C. W., and Hsu, Y. H. 1996. The open reading frame of Bamboo mosaic potexvirus satellite RNA is not essential for its replication and can be replaced with a bacterial gene. Proc. Natl. Acad. Sci. U.S.A. 93:3138-31342.

Neelman, L., Van Der Kuyl, A. C., and Bol, J. F. 1991. Role of Alfalfa mosaic virus coat protein gene in symptom formation. Virology 181:687693

Ozeki, J., Hashimoto, M., Komatsu, K., Maejima, K., Himeno, M., Senshu, H., Kawanishi, T., Kagiwada, S., Yamaji, Y., and Namba, S. 2009. The N-terminal region of the Plantago asiatica mosaic virus coat protein is required for cell-to-cell movement but is dispensable for virion assembly. Mol. Plant Microbe Interact. 22:677-685.

Peck, S. C., Nühse, T. S., Hess, D., Iglesias, A., Meins, F., and Boller, T. 2001. Directed proteomics identifies a plant-specific protein rapidly phosphorylated in response to bacterial and fungal elicitors. Plant Cell 13:1467-1475.

Revers, F., Gall, O. L., Candresse, T., and Maule, A. J. 1999. New advances in understanding the molecular biology of plant/potyvirus interactions. Mol. Plant Microbe Interact. 12:367-376.

Sambrook, J., Fritsch, F., and Maniatis, T. 2000. Molecular Cloning: A Laboratory Manual, 2nd ed. Cold Spring Harbor Laboratory Press. Cold Spring Harbor, NY, U.S.A.

Shintaku, M. H., and Palukaitis, P. 1992. A single amino acid substitution in the coat protein of Cucumber mosaic virus induces chlorosis in tobacco. Plant Cell 4:751-757.

Tenllado, F., and Bol, J. F. 2000. Genetic dissection of the multiple functions of alfalfa mosaic virus coat protein in viral RNA replication, encapsidation, and movement. Virology 268(1):29-40.

Tremaine, J. H., and Agrawal, H. O.1972. Limited proteolysis of Potato virus $X$ by trypsin and plant proteases. Virology 49:735-744.

Verchot-Lubicz, J., Ye, C.-M., and Bamunusinghe, D. 2007. Molecular biology of potexviruses: Recent advances. J. Gen. Virol. 88:1643-1655.

Yang, C. C., Liu, J. S., Lin, C. P., and Lin, N. S. 1997. Nucleotide sequence and phylogenetic analysis of Bamboo mosaic potexvirus isolate from common bamboo (Bambusa vulgaris McClure). Bot. Bull. Acad. Sin. 38:77-84.

Yang, C. D., Liao, J. T., Lai, C. Y., Jong, M. H., Liang, C. M., Lin, Y. L., Lin, N. S., Hsu, Y. H., and Liang, S. M. 2007. Induction of protective immunity in swine by recombinant Bamboo mosaic virus expressing foot-and-mouth disease virus epitopes. BMC Biotechnol. 7:62.

Zhang, H., Todderud, E., and Stubbs, G. 1993. Crystallization and preliminary X-ray analysis of Papaya mosaic virus coat protein. J. Mol. Biol. 234(3):885-887.

\section{AUTHOR-RECOMMENDED INTERNET RESOURCES}

ExPaSy Proteiomics server's PeptideCutter website: expasy.org/tools/peptidecutter/peptidecutter_enzymes.html MEGA 4 software (http://www.megasoftware.net/

MyHits Motif scan website: myhits.isb-sib.ch/cgi-bin/motif_scan

Pôle BioInformatique Lyonnaise network program sequence analysis database: Npsa-pbil.ibcp.fr/cgi-

bin/npsa_automat.pl?page=/NPSA/npsa_seccons.html 